\title{
Sensitivity analysis of deep geothermal reservoir: effect of reservoir parameters on production temperature
}

\author{
Musa D. Aliyu ${ }^{1}$ and Hua-Peng Chen ${ }^{1 *}$ \\ ${ }^{1}$ Department of Engineering Science, University of Greenwich, Chatham Maritime, Kent \\ ME4 4TB, U. K.
}

*Corresponding author: H.Chen@greenwich.ac.uk

\begin{abstract}
This study aims to guide reservoir engineers/managers in the selection of a combination of parameters from amongst various possible alternatives in developing deep geothermal reservoirs which can meet the desired temperature at the production wellhead for sustainable energy production. The work presents an approach for predicting the long-term performance of a deep geothermal reservoir using multiple combinations of various reservoir parameters. The finite element method and factorial experimental design are applied to forecast which of the parameters has the most influence on long-term reservoir productivity. The solver employed is validated using known analytical solution and experimental measurements with good agreement. After the validation, an investigation is then performed based on the Soultz lower geothermal reservoir. The results showed that fluid injection temperature is the parameter that influences the experiment the most during exploitation involving production temperature, whereas injection pressure rate happens to have a more significant impact on reservoir cooling.
\end{abstract}

Keywords: Deep geothermal reservoir; human-controlled parameters; naturally-occurring parameters; finite element modelling; factorial experimental design. 


\section{Introduction}

Geothermal energy production is, and for the predictable future will remain, one of the most important activities that can provide a solution to the current clean and sustainable energy demand in the world. The objective is to discover and produce energy located at a great depth in an efficient way by applying a synergy of various scientific disciplines (geology, geophysics, seismology, and reservoir engineering). In a deep geothermal system, reservoir rock parameters determine the value of accumulated heat and energy[1]. Their quantity and productivity also ascertain the value of the accumulated energy. In reservoir management, both production rate and producibility are functions of the rock and reservoir fluid parameters [2]. For example, the capacity of a well depends on rock parameters (permeability, porosity, reservoir thickness), on fluid properties (density, viscosity), on the well type (vertical, horizontal), and on the pressure drop applied at the bottom hole. Also, the productivity of a geothermal well depends, among other things, upon the permeability of reservoir formation to those fluids, and anything that increases the permeability of the formation will increase the rate of energy production. Injection fluid in geothermal energy exploitation is one of the most important parameters that can be controlled during operations. This is because the fluid is heated to a precise temperature before injection. Mostly, after extracting the fluid back for usage, it is then transferred to a cooling tower for reinjection/reuse. The wellhead pressure and its relation to the flow rate of fluid via the turbine is an additional parameter that must be considered when generating power from geothermal resources. Likewise, the well spacing is decided by an ease of drilling and also by the evidence that the geothermal resource enclosed by the well pattern must be extracted during an economically acceptable period of 30 years [3]. This factor is determined by the fluid properties, the well capacity, the reservoir parameters, and distribution. If the exploitation of a geothermal reservoir takes place by so-called enhanced geothermal system (EGS) methods (as in this study), the well spacing is significantly less than in the case of production via the primary method [4].

Therefore, the interaction of this parameter with others can provide deeper insight into reservoir management. For instance, permeability is one of the fundamental parameters of a reservoir that controls the fluid flow in a deep geological formation. Reservoir stimulation increases the permeability of a system due to stress perturbation taking place as exploitation proceeds. However, coupled hydro-thermal analyses is not a candidate to capture the effect of such changes in permeability when simulating, though varying the values can provide a close solution to the real life scenario. On the other hand, porosity is another parameter that contributes in enhancing reservoir productivity because it concerns the volume fraction of the 
rock matrix to the pore space [5]. It is tough to estimate the porosity values for an entire matrix block in deep reservoirs due specifically to the limitations of the current measuring techniques [6]. Thus, it is expected to range the porosity values and examine their effect on reservoir productivity. Thermal conductivity, on the other hand, signifies the ability of material to transfer heat [7]. In deep subsurface systems, the value of the thermal conductivity of a formation is dependent on temperature, pressure, and porosity [8].

It is observed from the literature [9]-[14] that, as far as the application of finite element heat transfer and fluid flow problems to geothermal energy are concerned, a lot of studies are available. However, no study appears to be available that deals with multiple parameter interactions in geothermal energy exploitation. Based on this, the objective of the present study is to explore the possible combination of critical parameters in a deep geothermal reservoir that can meet a certain production temperature requirement during a long-term simulation of 60 years. The work identifies two group of parameters, which are human-controlled and naturallyoccurring parameters, and their interactions provide preliminary indications of the potential productivity of a geothermal reservoir. A three-dimensional (3-D) model of the Soultz (France) deep geothermal reservoir is developed on COMSOL FE package, which is a commercial software that allows the implementation of user-defined subroutines from the MATLAB programming language in the simulation. The package is widely employed in industries and institutions for its capability to accommodate extensive material modelling and the coupling of several systems in finite element analyses. Before running the analysis, the numerical code is validated first with known analytical solution and experimental measurements to ascertain the capability of the chosen simulator. In the reservoir analysis, the required temperature fields are calculated by solving a forward problem using the finite element method. For predicting the possible combinations, a complete factorial experimental design is chosen for the analyses.

In this study, the sensitivity analysis is limited to the maximum and minimum values of the reservoir parameters analysed. Knowing the influence of a certain parameter under a minimum or maximum value when combined with other parameters will provide an understanding of which of the values is significant. Besides, it reduces the computational cost without compromising the outcome of the analysis. For example, lateral well spacing, as a human-controlled parameter when narrowly spaced, will likely result in short-circuiting, whereas wider spacing makes it harder to establish a connection between the wells. Therefore, careful considerations have to made when selecting the minimum or maximum value of the reservoir parameters. The various parameters are taken from the general engineering observation's point of view in the real field case for the Soultz geothermal reservoir. 


\section{Mathematical background}

The finite-element method is used for solving the macroscopic transient coupled equations of heat transfer and fluid flow in a fully saturated and fractured porous medium as implemented in the forward modelling code chosen. Thus, the dual porosity-permeability approach is employed in solving the macroscopic partial differential equations (PDE's) for both the matrix and fracture systems. In this approach, the rock matrix is considered to have high porosity and low permeability, while the fracture, on the contrary, has low porosity and high permeability. The irregular fracture system crossing the matrix provides perhaps the recovery of the accumulated heat and energy.

\subsection{Governing equations}

The macroscopic equations describing heat and fluid transport in fractured and saturated porous media can be numerically investigated by coupling the appropriate rock and fluid physical properties, respectively. For the heat transport, the transfer in porous matrix is governed by both conduction and convection [15], which is written as

$$
\rho C_{P} \frac{\partial T}{\partial t}+\rho_{L} C_{P, L} v \cdot \nabla T-\nabla(\lambda \cdot \nabla T)=0
$$

114

where $\rho$ and $C_{P}$ are the effective densities and specific heat capacities, respectively, $T$ is the temperature, and $t$ is time. Properties, $\rho_{L}$ and $C_{P, L}$ corresponds to fluid density and specific heat capacity, $v$ is Darcy's velocity and $\lambda$ is the effective thermal conductivities. The properties of the porous media obey a simple mixing rule between solid (S) and liquid (L), expressed as

$$
\begin{aligned}
& \rho C_{P}=\phi\left(\rho_{L} C_{P, L}\right)+(1-\phi) \rho_{S} C_{P, S} \\
& \lambda=\phi\left(\lambda_{L}\right)+(1-\phi) \lambda_{S}
\end{aligned}
$$

here $\phi$ is the porosity and $\rho_{s}$ is the solid density. Properties, $\lambda_{L}$ and $\lambda_{S}$ are the fluid and solid thermal conductivities, respectively.

For the fluid flow within a matrix block [16], the equation writes

$$
\rho_{L} S \frac{\partial P}{\partial t}+\nabla \cdot \rho_{L} v=0
$$


where $S$ is the linearised storage, and $P$ is the fluid pressure, and Darcy's velocity $v$ is written as

$$
v=-\frac{\kappa}{\mu}\left(\nabla P-\rho_{L} g \nabla z\right)
$$

here $\kappa$ is the permeability, $\mu$ is the fluid viscosity, $g$ is the acceleration due to gravity and $z$ is the depth.

Similarly, the heat transport in fractures within a porous matrix is given by

$$
\rho C_{P} \frac{\partial T}{\partial t}+\rho_{L} C_{P, L} v_{f} \cdot \nabla T-\nabla(\lambda \cdot \nabla T)+Q_{f, E}+Q_{m, E}=0
$$

parameters, $Q_{f, E}$ and $Q_{m, E}$ corresponds to the energy sources/sinks for the fracture and matrix block. The fracture Darcy's velocity term $v_{f}$ is expressed as

$$
v_{f}=-\frac{b^{2}}{12 \mu}\left(\nabla P_{f}-\rho_{L} g \nabla z\right)
$$

where $b$ is the fracture aperture, and $P_{f}$ is the fluid pressure within the fracture. The fluid flow within the fracture is written as

$$
\rho_{L} S_{f} \frac{\partial P_{f}}{\partial t}+\nabla \cdot \rho_{L} v_{f}+Q_{f}+Q_{m}=0
$$

where $Q_{f}$ and $Q_{m}$ are the fluid mass sources/sinks for the fracture and matrix block and $S_{f}$ is the fracture storativity.

Coupling between the fluid motion and heat transport is carried out through $\rho_{L}, \mu, C_{P, L}$, and $\lambda_{L}$ parameters that appear in almost all the Equations (1) - (8), which are coupled by the temperature field (T), since all the properties are temperature-dependent, which will be discussed later. Also, the coupling between heat transport and fluid flow is achieved through Darcy's velocity term (contribution of convective heat transfer) that appears in Equations (1), (4), and (5) for the matrix block, and (6), (7) and (8) for the fracture.

\subsection{Fluid and rock physical properties}


In this study, the fluid properties are assumed to vary with temperature. For the fluid density in $\mathrm{kg} / \mathrm{m}^{3}$, the fitting polynomial trend proposed by Holzbecher [17] has been chosen, and is written as

$$
\rho_{L}(T)=996.9\left(1-3.17 \times 10^{-4}(T-298.15)-2.56 \times 10^{-6}(T-298.15)^{2}\right)
$$

The temperature in equation (9), ranges from $20^{\circ} \mathrm{C}$ to $250^{\circ} \mathrm{C}$. The analytical expression adopted for the relationship between dynamic viscosity in Pa.s and temperature [18] given as

$$
\mu(T)=2.414 \times 10^{-5} \times 10^{\frac{247.8}{(T+133)}}
$$

In equation (10) the temperature ranges between 4 and $250^{\circ} \mathrm{C}$. For the thermal conductivity in $10^{3} \mathrm{~W} / \mathrm{m} / \mathrm{K}$, the following fitting polynomial is employed [3]

$$
\lambda_{L}(T)=-922.47+2839.5\left(\frac{T}{T_{0}}\right)-1800.7\left(\frac{T}{T_{0}}\right)^{2}+525.77\left(\frac{T}{T_{0}}\right)^{3}-73.44\left(\frac{T}{T_{0}}\right)^{4}
$$

where $T_{0}$ is $273.15 \mathrm{~K}$, and the temperature ranges between $0^{\circ} \mathrm{C}$ and $350^{\circ} \mathrm{C}$, and according to Holzbecher [17], specific heat capacity of fluid at temperatures between $100^{\circ} \mathrm{C}$ and $320^{\circ} \mathrm{C}$ can be approximated by

$$
C_{P, L}(T)=3.3774-1.12665 \times 10^{-2} T+1.34687 \times 10^{-5} T^{2}
$$

The unit of equation (11) is [cal $/ \mathrm{g} / \mathrm{K}]$, to obtain the SI units $[\mathrm{J} / \mathrm{kg} / \mathrm{K}]$ it has to be multiplied by 4187.6. Specific heat capacity below the temperature of $100^{\circ} \mathrm{C}$ seems to be constant with a value of $4200 \mathrm{~J} / \mathrm{kg} / \mathrm{K}$ approximately [17].

\section{Validations}

Before proceeding with the investigation, it is required to be first convinced that the numerical solutions are valid. The typical method of validating a numerical solution is to use a simple problem for which analytical solutions are available and, after that, to test the numerical solution with the chosen analytical solution. One of the main issues of this method is that it can only be employed in extremely simple problems because seeking to obtain the analytical solution of real problems is practically impossible. Apart from analytical solutions, the most common method used in validating a numerical simulation is through experimental measurements. This method is more reliable due to the fact that measurements show the consistency of the solution in reality. Thus, it is important to note that when an experiment is 
performed, a measuring instrument must be introduced; once employed, it directly or indirectly affects the system being measured. However, at the end of the validation process, it is crucial to have the greatest similarity between the measurement and numerical simulation.

Therefore, in this study, both the analytical and experimental measurements are employed in validating the numerical simulation chosen in this research as presented in the upcoming sections.

\subsection{Numerical validation of analytical solution}

The validation of the analytical model is based on heat diffusion and advection through a rock matrix orthogonal to a fracture, as shown in Fig. 1. Coupling of the advective 1D heat transport in the fracture and diffusive 1D heat transport in the rock matrix is also presented in the analytical solution. Thus, the rock matrix elements are linked to the fracture elements orthogonally, which implies that the nodes in the matrix are not influenced by their right or left boundaries. In the present study, the analytical solution, often referred to as Lauwerier's Solution, is examined and compared with numerical results concerning the temperature breakthrough curves at certain positions within the rock matrix. The analytical solution is derived based on the assumptions that heat is transferred only by advection in the fracture, and also, heat transfer takes place by diffusion in the rock matrix along the z-axis only [19]. Thus, the Lauwerier's solution is given by

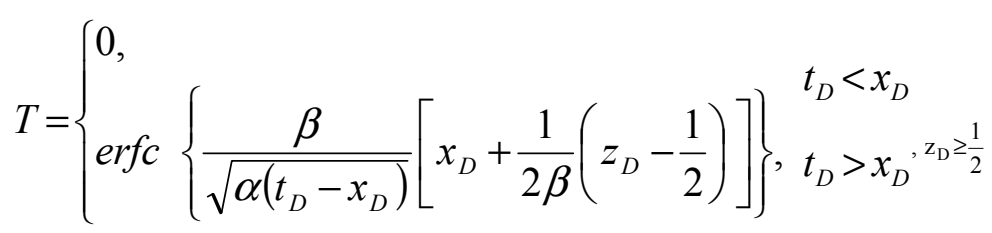

where the following parameters from equation (13) are dimensionless:

$$
t_{D}=\frac{v t}{b_{w}}, \quad x_{D}=\frac{x}{b_{w}}, \quad z_{D}=\frac{z}{b_{w}}, \quad \alpha=\frac{\lambda_{S}}{C_{p, S} \rho_{S}} \frac{1}{b_{w} v}, \quad \beta=\frac{\lambda_{S}}{C_{p, L} \rho_{L}} \frac{1}{b_{w} v}
$$

where $v$ is the groundwater velocity, $b_{w}$ is the fracture width, while $x$ and $z$ represents the dimensions of the axes.

Table 1 presents the model and material parameters employed in the study [19]. Fig. 2 shows the schematic description of the model and the relevant boundary conditions, but due to symmetry, only the domain above the x-axis is considered in the numerical investigations. Fig. 3 presents the locations of specific points chosen to observe the temperature breakthrough curves in order to assess the numerical simulation in comparison with the analytical solutions. 
Fig. 4 shows the numerical simulation results, compared to the analytical solution at the three chosen points on the rock matrix. The plotted temperature breakthrough curves and the time are both considered to be dimensionless parameters. At the observed points, it can be seen that there are slight differences between the numerical results and the analytical solutions, but after some time, both solutions fit very well. The cause for the slight deviation between the analytical solution from the numerical results is because at the early simulation period (200 and 400), the breakthrough temperature of the numerical model points far from the fractures are not affected by the fluxes at the fracture's edge due to different modelling assumptions of fracture flow. The analytical model assumed the fracture to be an equivalent porous medium whereas the numerical model used the cubic law of parallel plates. However, after a longer period of simulation $(600,800$, and 1000$)$, both results fit very well together.

In addition, another possible reason for the primary difference may likely be due to the inclusion of a viscosity parameter in the numerical simulations, which is not present in the analytical solution. In summary, it is concluded that both the numerical simulation and analytical solution are in good agreement.

\subsection{Validation of temperature profile at Soultz well}

In line to carry out a validation study on a geothermal system, the lower granite of the Soultz geothermal system is chosen due to the situation of the lower reservoir within this vicinity. Thus, validation of the temperature profile of this lower section of the system is paramount in justifying the validity of the proposed model. A steady-state simulation is carried out on the Soultz geothermal system to validate the proposed model by predicting the temperature profile variation with depth. The measured temperature profile at Soultz wells are reported in works of literature [20], [21]. The predicted temperature profile proposed at a depth of the lower granite in Soultz (i.e., $3.5 \mathrm{~km}$ to $5.4 \mathrm{~km}$ ) is compared to the recorded data obtained at well

Table 2 presents the percentage difference between the measured and simulated temperature profile at well GPK2. As seen, from the depths observed, the maximum deviation is $3.19 \%$, and the minimum difference is $0 \%$. These differences in temperature profile could be attributed to the following reasons. (1) Both Heat and fluid flow are modelled at steady state; therefore, energy loss due to the acceleration of fluid is not accounted. (2) Non-uniform fluid 
properties and geological formations having different thermal properties may likely influence the deviations between the results. (3) Other possible effects such as chemical and mechanical interactions presented during the measurements are not captured in the simulations.

It is also important to note that only measured values of the density, porosity, and permeability from the sample cores obtained from the wellbores are employed as inputs to this model.

\section{Case study: Soultz geothermal reservoir}

The interest generated by the Fenton Hill geothermal project resulted in several experimental studies in the European countries (the United Kingdom, Germany, and France), and due specifically to the high cost of large-scale experiments, an agreement was reached by the European countries to pool both financial and manpower resources on a single site with the aim to develop a commercial demonstration project within Europe [22]. The European Commission coordinated the selection of the most suitable of the three major sites (Rosemanowes, Soultz, and Bad Urach) and decided to locate the project to Soultz in 1987. The European Commission initially funded the project with the help of relevant energy ministries from France, the United Kingdom, and Germany [23]-[25]. The Soultz project is developed in three major stages: the preliminary stage (1984-1987), the drilling and exploration stage (1987-2007), and the power plant construction stage (2007-2008) [26]. However, the goal of this study is to model the lower geothermal reservoir, which happens to fall during the second stage of the project. Fig. 6 showed the schematic diagram of the Soultz triplet geothermal system [27]. As can be seen, the wells are drilled from the same platform on the surface, with a lateral distance of $6 \mathrm{~m}$ between each well. On the other hand, at the bottom hole, the lateral distance between each of the production wells from the injection well is $0.6 \mathrm{~km}$ [28]. The wells are fully cased from the surface down to the top of the lower reservoir level $(4.5 \mathrm{~km})$, whereas there is an open hole section of about $0.5 \mathrm{~km}$ in length from the starting point of the lower reservoir, with an 8.5-inch diameter [29]. Regarding fractures, three categories exist within the lower reservoir, ranging from active to non-active [30], [31], but here, only one active fracture is considered.

\subsection{Geometrical and physical properties of the reservoir}

An ideal numerical model of the lower reservoir has been developed to simplify the calculations, as shown in Fig. 7. In order to investigate the physical variation such as pressure and temperature in the rock matrix induced as a result of extraction processes from the hot dry 
rock (HDR); it is significant to understand the changes of the physical features, not only amid the fracture but also between the rock matrix and the fracture, simultaneously. In achieving these goals, a fracture is introduced in the model to clarify the physical model and reduce the computational workload. The fracture intersects at a depth of $4.77 \mathrm{~km}$, the coordinates of the fracture $(0.15-1.8 \mathrm{~km}, 0.25 \mathrm{~km}, 4.5-5.1 \mathrm{~km})$ with an inclined angle of $60^{\circ}$. The injection well GPK3, in the lower reservoir, is at coordinates $(1 \mathrm{~km}, 0.25 \mathrm{~km}, 4.5-5.1 \mathrm{~km})$; the coordinates of the first production well GPK2 are $(1.5 \mathrm{~km}, 0.25 \mathrm{~km}, 4.5-5 \mathrm{~km})$ with an inclination angle of $10^{\circ}$. The coordinates for the second production well GPK4 $(0.5 \mathrm{~km}, 0.25 \mathrm{~km}, 4.5-5.1 \mathrm{~km})$ have an inclination angle of $-10^{\circ}$.

For the rock petrophysical properties (thermal conductivity, density, porosity, permeability and heat capacity) of the Soultz (France) lower geothermal reservoir (4.5-5.0 km) are taken from literature and previous hypotheses [15], [32], [33], and are provided in Table 3.

\subsection{Initial and boundary conditions}

The temperature profile of the Soultz geothermal system possesses a dynamic gradient trend. The upper formation (i.e. $0-1.0 \mathrm{~km}$ ) holds a gradient of $110^{\circ} \mathrm{C} / \mathrm{km}$, whereas the intermediate (i.e. 1-3.5 km) and lower formations (i.e. $3.5-5.3 \mathrm{~km}$ ) possess gradients of $5^{\circ} \mathrm{C} / \mathrm{km}$ and $30^{\circ} \mathrm{C} / \mathrm{km}$, respectively [34]. Given that this study is concerned with lower reservoir modeling with a bottom hole temperature of $200^{\circ} \mathrm{C}$, to achieve the targeted bottom hole temperature in the lower reservoir, a gradient of $38^{\circ} \mathrm{C} / \mathrm{km}$ is adopted for the investigations. The initial temperature is expressed as

$$
T_{0}(z)=12^{\circ} \mathrm{C}-38^{\circ} \mathrm{C} / \mathrm{km} \times(-z)
$$

where $T_{0}(z)$ is the initial temperature of the reservoir, $12^{\circ} \mathrm{C}$ is the assumed value of the surface temperature, $38^{\circ} \mathrm{C} / \mathrm{km}$ is the geothermal gradient, and $z$ is depth in kilometres. The initial pressure is assumed to be hydrostatic throughout the reservoir.

A Dirichlet boundary condition (BC) of $30^{\circ} \mathrm{C}$ (injection temperature) is applied as a thermal boundary condition, whereas for the hydraulic case, $10 \mathrm{MPa}$ (injection pressure) was considered as the Dirichlet BC on the wellbore injection GPK3. On the other hand, an underpressure $\mathrm{BC}$ of $-10 \mathrm{MPa}$ is employed on both the production wells GPK2 and GPK4, individually. All other boundaries remain insulated during simulations.

\subsection{Meshing and solutions}


To obtain a reliable finite element solution, a well-defined meshing technique is required. In particular, in deep reservoir modelling, several structures are considered with highly varying scales. For example, in the interaction between reservoir wells and rock matrix, the former is in millimetres, whereas the latter is in thousand meters or kilometres. Thus, meshing structures of this kind necessitate a special approach. In this study, isoparametric elements are chosen for meshing the various reservoir components. A four-node tetrahedral element is adopted for the discrete of the matrix, a three-node triangular element for the fractures, and a two-node line element for the wells. Extremely fine, extra fine, and finer grids are employed to scatter computation vicinity. The major complexity of this meshing approach lies in maintaining the internal geometric uniformity between well, fracture, and matrix elements.

In Fig. 8, finer grids of moderate element size scatter the matrix domain and its boundaries far away from the fracture and the wellbores, whereas extra fine grids are created within the fracture and the neighbouring matrix attached to it. For the wellbores, extremely fine grids are employed by regulating the element growth rate between the wellbores, fracture, as well as the rock matrix, as shown in Fig. 8. Fig. 8 also presents the element size distribution of the reservoir model. As can be seen in the figure, the minimum element size is $0.14 \mathrm{~m}$, and the maximum size is $84.6 \mathrm{~m}$. The distribution depends on a structural dimension; for example, the wellbore that has the slender dimension and the elements within its region are smaller in size in comparison to the fracture and matrix elements. The mesh generated results in 966,213 tetrahedrons, 41,904 triangulars, 3,272 edges, and 58 vertex elements. The mesh division approach improves the calculation precision and also eliminates the deviation rate induced by unsuitable selected boundary conditions.

The simulation is run for 60 years, and because of the long simulation time and the stability provided by the constant temperature and pressure conditions, a backwards difference formula (BDF) is employed in the COMSOL package. The scheme holds an advantage of limiting time step. In the present study, it took only 47 time steps to simulate the 60 -year experimentation. The physical memory used for the simulation is $3750 \mathrm{MB}$, and the virtual memory is $3980 \mathrm{MB}$.

\section{Results and Discussions}

After successful completion of the validation studies, this study seeks to identify some response parameters that govern the behaviour of geothermal reservoirs subjected to different operational conditions, as well as to assess their long-term performance. The proposed methodology consists of using a 3-D model of the Soultz lower geothermal reservoir to 
comprehend the result of interactions between several independent parameters in geothermal energy exploitations by employing a complete factorial experimental design.

In predicting a possible combination, the value ranges for various reservoir parameters are chosen based on previous field experiments conducted at Fenton Hill (US), Rosemanowes (UK), Hijori and Ogachi (Japan), and Soultz (France) geothermal projects. These can all be found in the MIT report [22]. For instance, it is known from field experience that thermal conductivity of most of the rocks falls within 1.0 to $3.5 \mathrm{~W} / \mathrm{m} / \mathrm{K}$. Similarly, for porosity, the same has also been assumed to lie between $10 \%$ to $40 \%$ for most formations. In a similar context, different value ranges are prescribed for rock permeability $(0.1 \mathrm{mD}-0.01 \mathrm{mD})$ and geothermal gradient $\left(28^{\circ} \mathrm{C} / \mathrm{km}-38^{\circ} \mathrm{C} / \mathrm{km}\right)$.

In the case of human-controlled parameters, the injection pressure selection depends on the value of measured minimum principal stress to create hydraulic fractures. In this study, the choice of maximum and minimum injection pressure (10 MPa - 25 MPa) is based on the Soultz and Fenton Hill projects, respectively. Similarly, for injection temperature, the values gathered for most reservoirs lie between $30^{\circ} \mathrm{C}$ and $60^{\circ} \mathrm{C}$. Also, different value ranges are prescribed for the injection flow rate $(10 \mathrm{l} / \mathrm{s}-70 \mathrm{l} / \mathrm{s})$, and lateral well spacing $(0.3 \mathrm{~km}-0.6 \mathrm{~km})$.

Table 4 presents the human-controlled parameters chosen for the studies, for each of the parameters the values ranges from minimum to maximum as mentioned above. Thus, two values are assigned to each individual parameter and all the possible combinations of other parameters in the same group are evaluated. The number of runs required for each group is $2^{n}$; this identifies the number of parameters $(n)$, how many levels each parameter has (2), and how many experimental conditions there are in the design $\left(2^{n}\right)$. Each independent parameter is a factor in the design because there are four parameters and each parameter has two levels of factorial design in each group.

Similarly, Table 5 presents the naturally occurring parameters with their minimum and maximum values using the same factorial experimentations design as in the human controlled parameters. Thus, this studies will have $2^{n}=16$ different experimental conditions for each of the human-controlled parameters, and naturally-occurring parameters as presented in Tables 6 and 7.

It is worthy to mention that, the temperature in the production wellbores GPK2 and GPK4 are found to be identical in all cases. Thus, for clarity purposes, only the simulation results obtained in production wellbore GPK2 are presented here. 


\subsection{The effect of human-controlled parameters on production temperature}

376 A complete factorial experimental design is used in implementing the possible combinations required, and for this case, it results to 16 different operational scenarios as shown in Table 6. The studies involve understanding the effect of various interactions of these parameters on reservoir productivity. Fig. 9a showed the production temperature history at wellhead GPK2, during the long-term simulation of 60 years for the Soultz lower reservoir, under the influence of multiple parameter interactions for the human-controlled parameters. Four interaction scenarios are considered by varying the injection temperatures and pressures while keeping the injection rate $(10 \mathrm{l} / \mathrm{s})$ and lateral well spacing $(0.3 \mathrm{~km})$ at a constant rate. As can be seen, lower injection temperature, when interacting with lower injection pressure, yields maximum production temperatures at the wellhead. The reason for that is the propagation of cold water is much slower under moderate pressure than the higher one, as in the case of $30^{\circ} \mathrm{C}$ injection temperature with $10 \mathrm{MPa}$ injection pressure. On the other hand, higher pressure injection with higher injection temperature results in faster reservoir cooling and yields rapid decline in the production temperature, as seen in the scenario $25 \mathrm{MPa}$ injection pressure with $60^{\circ} \mathrm{C}$ injection temperature.

Similarly, further simulation investigations are carried out by changing only the injection rate from $10 \mathrm{l} / \mathrm{s}$ to $70 \mathrm{l} / \mathrm{s}$ under similar lateral well spacing of $0.3 \mathrm{~km}$, by varying the results as in the Fig. 9a, which means that the injection rate has no significance to the simulation results; this is likely due to the impact of the injection pressure applied to the reservoir.

Fig. $9 \mathrm{~b}$ presents the temperature profile at the production wellhead GPK2 for humancontrolled parameters case two. In this case, the parameters that are kept constant are the lateral well spacing $(0.6 \mathrm{~km})$ and the injection rate $(10 \mathrm{l} / \mathrm{s})$ while the injection temperatures and pressures are varied throughout the simulations. The influence of parameter interaction is observed to be similar to the previous case, but the production temperature drawdown is more realistic in comparison to the previous case as shown in Fig. 9a. In the scenario, $30^{\circ} \mathrm{C}$ injection temperature with $10 \mathrm{MPa}$ injection pressure, the production wellhead temperature decline is less than $1 \%$ as seen in Fig. $9 \mathrm{~b}$. On the other hand, when both the injection temperature and pressure are increased to $60^{\circ} \mathrm{C}$ and $25 \mathrm{MPa}$, respectively, a rapid decline is experienced. The decline starts just before the simulation reaches ten years, and from then onward, a constant decline rate is experienced up to the end of the simulation. 

rate to $70 \mathrm{l} / \mathrm{s}$ while all other parameters remain the same, and the results happen to be exactly as in the previous case.

\subsection{Parameter influence on reservoir cooling}

412 In order to investigate which of the human-controlled parameters is the most influencing in cooling the reservoir, different scenarios are run with varying injection pressure rate and fluid injection temperature rate under a constant lateral well distance of $0.6 \mathrm{~km}$, as shown in Fig. 10a-d. As can be seen, the lower the pressure, the less the effect of cooling, whereas with higher injection pressure rates, the larger the cooling. The low-temperature fluid from the injection well flows into the extraction well via the fracture; the fluid temperature rises through convection and conduction from the high-temperature matrix, resulting in superheated fluid in the extraction well. The significant temperature variation between the injected fluid temperature (low-temperature) and the matrix temperature (high-temperature) rapidly decreases the matrix temperature surrounding the injection well. Thus, a relatively lowtemperature area is formed during the initial operation, as seen in Fig. 10a-d. The reservoir temperature gradually decreases as the exploitation continues, while the low-temperature area gradually expands. Therefore, it can be concluded that the most influencing parameter concerning the cooling of the reservoir is the injection pressure rate. To summarise the results of the above cases, the higher the temperature of the fluid at the injection wellhead when it interacts with any sufficient injection pressure that can create new hydraulic fractures under a large well spacing, the lesser the temperature decline at the production wellhead, and viceversa.

It is observed in Fig. 9a-b and 10a-d that, higher injection pressure causes rapid cooling of the reservoir. This is because the increase of injection pressure transmits the injected fluid faster due to more openings in the reservoir and the injected fluid is at relatively low temperature. Thus, the temperature differences between the reservoir and the injected fluid will decrease with time due to cooling of the reservoir. The cold water front will propagate in the reservoir, and it gradually penetrates the production well and causes the decline in the production temperature with time. In the case of flow rate, the injection flow rate is inversely proportional to the injection pressure as proven experimentally at the Tianjin geothermal field in China [35]. In general, as the injection pressure increases, the injection flow rate decreases and vice-versa. 


\subsection{The effect of naturally-occurring parameters on production temperature}

442 In order to examine the effect of different interactions of the naturally-occurring parameters listed in Table 5 on reservoir productivity, a complete factorial experimental design is employed, and it rises to 16 distinct operational scenarios are shown in Table 7. The parameters examined include the geothermal gradient, permeability, thermal conductivity, and porosity. The results obtained are shown in Fig. 11 and are analysed using four different scenarios. In the first case, a constant geothermal gradient of $28^{\circ} \mathrm{C} / \mathrm{km}$ and permeability of $1 \mathrm{mD}$ are employed, while the other two parameters (i.e. thermal conductivity and porosity) are varied as presented in Fig. 11a. It is clear from Fig. 7a that there is a decline in the production temperatures in the first two cases, which is due specifically to the lower value of the thermal conductivities. In the first instance, the decline starts just close to 20 years of simulation, while in the second case, it just begins after 30 years of simulations. The reason for this difference is because the porosity in the first scenario is just $10 \%$, while in the second scenario, it is about $40 \%$, as the latter case provides more room for temperature circulation than the former.

In the second case, all other parameters remain the same as in the first instance except the permeability, which is changed from $1 \mathrm{mD}$ to $0.01 \mathrm{mD}$. Fig. $11 \mathrm{~b}$ presents the results for the case, and the maximum temperature obtained at production wellhead GPK2 is approximately equal to $143^{\circ} \mathrm{C}$ at about 20 years of simulation. The production temperature begins to decline in only two cases where the thermal conductivities are very low. The scenario with lower porosity starts to decrease around 19 years of simulation, while the other with higher porosity begins at about 31 years of simulation. In cases with higher thermal conductivities, the production temperatures are stable throughout the simulation period.

Similarly, further experimental simulations are carried out by changing the geothermal gradient from $28^{\circ} \mathrm{C} / \mathrm{km}$ to $38^{\circ} \mathrm{C} / \mathrm{km}$ while all other parameter combinations remain the same as in the previous two cases. Fig. 11c presents the production temperature profile at wellhead GPK2 for the instance where the geothermal gradient $\left(38^{\circ} \mathrm{C} / \mathrm{km}\right)$ and the permeability $(1 \mathrm{mD})$ are considered at constant rates, and the other parameters (i.e., thermal conductivity and porosity) are varied throughout the studies. The production temperature curves are similar to the curves shown in Fig. 11a and b, but the produced temperatures are higher in this case due to the increase in the geothermal gradient as seen in both Fig. 11c and d.

Furthermore, additional numerical simulations are conducted by changing the permeability to $0.01 \mathrm{mD}$ while all the remaining parameters are the same, and the results appear to be similar as in the previous case with some little changes in the production temperature values due specifically to the alterations in the permeability value. 
The reasons for the increase in the production temperature during the first 20 years of exploitation are numerous, among which are the geothermal gradient in the reservoir combined with the effect of significant horizontal distance between the injector and the producer. Also, the production wellbore being narrower among the reservoir component with lower fluid temperature before pumping begins, immediately the pumping starts the fluid hotter than that at the production wellbore is then added to the initial fluid temperature and keeps the temperature to rise until cooling begins. In this case, the cold water front starts to influence the produced temperature at approximately 20 years of exploitations.

The simulation experimentation results show that the thermal conductivity is the most influencing parameter regarding the production temperature because of its direct relationship with permeability, as confirmed by experimental studies; as the permeability increases, the thermal conductivity rises [36]. The simulation also indicates that porosity has the least effect concerning the reservoir's productivity, compared to the other parameters. Overall, the naturally-occurring parameters analysed in this study showed that the parameters contribute less to reservoir temperature decline because of temperature drawdown, after 60 years of simulation, of $2^{\circ} \mathrm{C}$ (for the worst case scenario). It is also evident that heat generation, in this case, will be more stable. The temperature production requirement proposed has been achieved in all the 16 scenarios investigated in this case.

\section{Findings and limitations}

The sensitivity analysis performed showed that reservoir parameters could be a significant asset to reservoir engineers/managers during planning, exploration, and exploitation stages. the parameters analysed are divided into two sets: the first category is referred to as humancontrolled parameters, which are fluid injection temperature, injection pressure rate, injection rate, and well lateral spacing, whereas the second type is called naturally-occurring parameters that include permeability, porosity, geothermal gradient, and thermal conductivity.

Based on the results obtained in this investigation for naturally-occurring parameters, it is clear that formation porosity has no significant effect on reservoir productivity regarding the naturally-occurring parameters. On the other hand, the reservoir permeability, geothermal gradient, and thermal conductivity have a major impact on reservoir productivity. This study showed that the permeability and the geothermal gradient of the reservoir are the important naturally-occurring parameters of the system.

For human-controlled parameters, the injection temperature, injection pressure, and 508 lateral well spacing have the most significant influence on reservoir productivity. Thus, the 
injection temperature, the injection pressure, and lateral well spacing are critical humancontrolled parameters that can be engineered to obtain the highest temperature production rate. Moreover, the study showed that there is a distinct trend in the variation of the production temperature with the change of each parameter. Based on the sensitivity analysis performed, two points are worth noting:

(1) The proper knowledge of the geothermal gradient and reservoir permeability are crucial factors in geothermal energy mining.

(2) The injection pressure has to be managed correctly because higher injection rates affect the reservoir productivity immensely.

Thus, the interactions between the parameters investigated in this work should be considered in relation to their effect on the production temperature and not on the financial viability or efficiency of the operation. For instance, the porosity does not affect reservoir productivity, but with respect to drilling operations, the more porous the formation, the less the operational cost and vice-versa.

\section{Conclusions}

Based on the geothermal energy plan of the Soultz (France) geothermal field, a 3-D numerical model has been developed for the lower reservoir $(4.5-5 \mathrm{~km})$ to examine the long-term performance of the reservoir using the finite element and factorial experimental design methods. With the factorial experimental design, various possible combinations of the reservoir parameters have been found, and their suitability is confirmed by comparing temperature histories at the production wellbores for the whole scenarios. The human-controlled parameters happen to have the most unstable temperature distribution at the production wells, and the most affected parameter regarding that is the fluid injection temperature. On the other hand, the naturally occurring parameters showed stable temperature distribution at the production wells in almost all the scenarios. Hence, the results obtained reveal that the reservoir parameters, if properly managed, can help decision makers maximise reservoir productivity.

\section{Acknowledgement}

The first author appreciates the $\mathrm{PhD}$ scholarship funding support gained from both the University of Greenwich (UK) and the Petroleum Technology Development Fund (PTDF) (Nigeria). 


\section{References}

544 [1] C. Jain, C. Vogt, and C. Clauser, "Maximum potential for geothermal power in Germany based on engineered geothermal systems," Geotherm. Energy, vol. 3, no. 1, p. $15,2015$.

[2] A. Sowiżdżał and M. Kaczmarczyk, "Analysis of thermal parameters of Triassic, Permian and Carboniferous sedimentary rocks in central Poland," Geol. J., vol. 51, no.

[8] R. DiPippo, Geothermal Power Plants : Principles, Applications, Case Studies and Environmental Impact Third Edition, 3rd ed. Waltham, USA: Elsevier Ltd., 2012.

[9] N. Watanabe, W. Wang, J. Taron, U. J. Görke, and O. Kolditz, "Lower-dimensional interface elements with local enrichment: application to coupled hydro-mechanical problems in discretely fractured porous media," Int. J. Numer. Methods Eng., vol. 90, no. March, pp. 1010-1034, Apr. 2012.

[10] M. D. Aliyu, H. Chen, and O. Harireche, "Finite element modelling for productivity of geothermal reservoirs via extraction well," in Proceedings of the 24th UK Conference of the Association for Computational Mechanics in Engineering 31 March-01 April 2016, Cardiff University, Cardiff, 2016, no. April, pp. 331-334.

[11] W. L. Cheng, C. L. Wang, Y. Le Nian, B. B. Han, and J. Liu, “Analysis of influencing factors of heat extraction from enhanced geothermal systems considering water 
losses,” Energy, vol. 115, pp. 274-288, 2016.

[12] W. L. Cheng, J. Liu, Y. Le Nian, and C. L. Wang, "Enhancing geothermal power generation from abandoned oil wells with thermal reservoirs," Energy, vol. 109, pp. 537-545, 2016.

[13] Y. Zeng, J. Zhan, N. Wu, Y. Luo, and W. Cai, "Numerical simulation of electricity generation potential from fractured granite reservoir through vertical wells at Yangbajing geothermal field,” Energy, vol. 103, pp. 290-304, May 2016.

[14] S. Kelkar, K. Lewis, S. Karra, G. Zyvoloski, S. Rapaka, H. Viswanathan, P. K. Mishra, S. Chu, D. Coblentz, and R. Pawar, "A simulator for modeling coupled thermo-hydromechanical processes in subsurface geological media," Int. J. Rock Mech. Min. Sci., vol. 70, pp. 569-580, 2014.

[15] M. D. Aliyu and H. Chen, "Numerical Modelling of Coupled Hydro-Thermal Processes of the Soultz Heterogeneous Geothermal System," in ECCOMAS Congress 2016 VII European Congress on Computational Methods in Applied Sciences and Engineering M. Papadrakakis, V. Papadopoulos, G. Stefanou, V. Plevris (eds.) Crete Island, Greece, 5-10 June 2016, 2016, no. June, pp. 1-13.

[16] D. Dempsey, S. Kelkar, and K. Lewis, "Modeling Shear Stimulation of the Desert Peak EGS Well 27-15 Using a Coupled Thermal-Hydrological-Mechanical Simulator," 47th US Rock Mech. Symp., no. JUNE, pp. 1-15, 2013.

[17] E. O. Holzbecher, Modeling Density-Driven Flow in Porous Media. Berlin, Heidelberg: Springer Berlin Heidelberg, 1998.

[18] M. Rabinowicz, J. Boulègue, and P. Genthon, "Two- and three-dimensional modeling of hydrothermal convection in the sedimented Middle Valley segment, Juan de Fuca Ridge,” J. Geophys. Res. Solid Earth, vol. 103, no. B10, pp. 24045-24065, Oct. 1998.

[19] O. Kolditz, U.-J. Görke, H. Shao, and W. Wang, Thermo-Hydro-Mechanical-Chemical Processes in Porous Media: Benchmarks and Examples, vol. 86. Berlin, Heidelberg: Springer Berlin Heidelberg, 2012.

[20] A. Genter, C. Castaing, C. Dezayes, H. Tenzer, H. Traineau, and T. Villemin, "Comparative analysis of direct (core) and indirect (borehole imaging tools) collection of fracture data in the Hot Dry Rock Soultz reservoir (France)," J. Geophys. Res., vol. 102, no. B7, pp. 15419-15431, 1997.

[21] V. Spichak, J. Geiermann, O. Zakharova, P. Calcagno, A. Genter, and E. Schill, "Estimating deep temperatures in the Soultz-sous-Forêts geothermal area (France) from magnetotelluric data," Near Surf. Geophys., vol. 13, no. 2089, pp. 397-408, Jul. 
2015.

[22] MIT, “The Future of Geothermal Energy,” Idaho, USA, 2006.

[23] J. Charléty, N. Cuenot, L. Dorbath, C. Dorbath, H. Haessler, and M. Frogneux, "Large earthquakes during hydraulic stimulations at the geothermal site of Soultz-sousForêts,” Int. J. Rock Mech. Min. Sci., vol. 44, no. 8, pp. 1091-1105, Dec. 2007.

[24] S. Held, A. Genter, T. Kohl, T. Kölbel, J. Sausse, and M. Schoenball, "Economic evaluation of geothermal reservoir performance through modeling the complexity of the operating EGS in Soultz-sous-Forêts," Geothermics, vol. 51, pp. 270-280, Jul. 2014.

[25] A. Genter, K. Evans, N. Cuenot, F. Baticci, L. Dorbath, J. Graff, and B. Sanjuan, "The EGS Soultz project (France): From reservoir development to electricity production," Trans. - Geotherm. Resour. Counc., vol. 33, no. October, pp. 346-351, 2009.

[26] A. Genter, K. Evans, N. Cuenot, D. Fritsch, and B. Sanjuan, "Contribution of the exploration of deep crystalline fractured reservoir of Soultz to the knowledge of enhanced geothermal systems (EGS)," Comptes Rendus Geosci., vol. 342, no. 7-8, pp. 502-516, 2010.

[27] A. Genter, J. Baumgärtner, N. Cuenot, J. J. Graff, T. Kölbel, and B. Sanjuan, “The EGS case study : lessons learnt after two decades of geothermal researches .," in Second European Geothermal Review-Geothermal Energy for Power Production, June 21-23, 2010, Mainz, Germany, 2010, no. June 2010, pp. 4-7.

[28] C. Dezayes, S. Gentier, and A. Genter, "Deep Geothermal Energy in Western Europe: The Soultz Project," France, 2005.

[29] A. Genter, X. Goerke, J. Graff, N. Cuenot, G. Krall, M. Schindler, and G. Ravier, "Current Status of the EGS Soultz Geothermal Project ( France )," in World Geothermal Congress, 2010, vol. C, no. April, pp. 25-29.

[30] C. Dezayes, A. Genter, and B. Valley, "Structure of the low permeable naturally fractured geothermal reservoir at Soultz," Comptes Rendus Geosci., vol. 342, no. 7-8, pp. 517-530, Jul. 2010.

[31] J. Sausse, C. Dezayes, L. Dorbath, A. Genter, and J. Place, "3D model of fracture zones at Soultz-sous-Forêts based on geological data, image logs, induced microseismicity and vertical seismic profiles," Comptes Rendus Geosci., vol. 342, no. 7-8, pp. 531-545, Jul. 2010.

[32] L. Guillou-Frottier, C. Carrè, B. Bourgine, V. Bouchot, and A. Genter, "Structure of hydrothermal convection in the Upper Rhine Graben as inferred from corrected 
temperature data and basin-scale numerical models," J. Volcanol. Geotherm. Res., vol. 256, no. July 2016, pp. 29-49, Apr. 2013.

[33] V. Magnenet, C. Fond, A. Genter, and J. Schmittbuhl, “Two-dimensional THM modelling of the large scale natural hydrothermal circulation at Soultz-sous-Forêts," Geotherm. Energy, vol. 2, no. 1, p. 17, Dec. 2014.

[34] J. Vidal, A. Genter, P. Duringer, J. Schmittbuhl, U. De Strasbourg, R. Descartes, and F.-S. Cedex, "Natural Permeability in Fractured Triassic Sediments of the Upper Rhine

[35] W. Kun, "Studies of the Reinjection Tests in Basement Geothermal Reservoir, Tianjin , China," in Proceedings World Geothermal Congress 2005 Antalya, Turkey, 24-29 April 2005, 2005, no. April, pp. 1-6.

[36] W. Bujakowski, A. Barbacki, M. Miecznik, L. Pająk, R. Skrzypczak, and A. Sowiżdżał, "Modelling geothermal and operating parameters of EGS installations in the lower triassic sedimentary formations of the central Poland area," Renew. Energy, 661 
Table 1: Model parameters used for the analytical validations [19]

\begin{tabular}{|c|c|c|}
\hline Parameter & Value & Symbol \\
\hline \multicolumn{3}{|l|}{ Spatial discretisation } \\
\hline Fracture length (m) & 50 & $L$ \\
\hline Fracture width (m) & $2 e-3$ & $b$ \\
\hline Matrix width (m) & 63.25 & $W$ \\
\hline Increment size $\mathrm{x}$-axis & 2 & $d x$ \\
\hline Increment size $\mathrm{z}$-axis & 0.1265 & $d z$ \\
\hline \multicolumn{3}{|l|}{ Material properties } \\
\hline Matrix porosity (\%) & 1.0 & $\phi$ \\
\hline Matrix permeability $\left(\mathrm{m}^{2}\right)$ & $1 e-15$ & $\kappa$ \\
\hline Thermal conductivity $(\mathrm{W} / \mathrm{m} / \mathrm{K})$ & 3.0 & $\lambda_{s}$ \\
\hline Solid heat capacity $(\mathrm{J} / \mathrm{kg} / \mathrm{K})$ & 1000 & $C_{\rho, S}$ \\
\hline Fluid heat capacity $(\mathrm{J} / \mathrm{kg} / \mathrm{K})$ & 4000 & $C_{\rho, L}$ \\
\hline Solid density $\left(\mathrm{kg} / \mathrm{m}^{3}\right)$ & 2600 & $\rho_{s}$ \\
\hline Fluid density $\left(\mathrm{kg} / \mathrm{m}^{3}\right)$ & 1000 & $\rho_{L}$ \\
\hline \multicolumn{3}{|l|}{ Initial conditions } \\
\hline Pressure $(\mathrm{Pa})$ & $1 \mathrm{e}+5$ & $P_{-}$in \\
\hline Temperature $\left({ }^{\circ} \mathrm{C}\right)$ & 0 & $T_{-}$in \\
\hline \multicolumn{3}{|l|}{ Boundary conditions } \\
\hline Injection Temperature $\left({ }^{\circ} \mathrm{C}\right)$ & 1.0 & $T_{-} i n j$ \\
\hline Inlet velocity $(\mathrm{m} / \mathrm{s})$ & $1 e-3$ & $v$ \\
\hline Production pressure & $1 \mathrm{e}+5$ & $P_{-}$pro \\
\hline
\end{tabular}


Table 2: Percentage difference between measured and simulated temperature profile at GPK2

\begin{tabular}{llll}
\hline $\begin{array}{l}\text { Vertical } \\
\text { depth }(\mathbf{m})\end{array}$ & $\begin{array}{l}\text { Measured } \\
\text { temperature }\left({ }^{\circ} \mathbf{C}\right)\end{array}$ & $\begin{array}{l}\text { Simulated } \\
\text { temperature }\left({ }^{\circ} \mathbf{C}\right)\end{array}$ & $\begin{array}{l}\text { Percentage } \\
\text { difference (\%) }\end{array}$ \\
\hline-3570 & 149 & 147 & 1.35 \\
-3730 & 159 & 154 & 3.19 \\
-4030 & 168 & 165 & 1.80 \\
-4400 & 179 & 179 & 0.00 \\
-4760 & 191 & 193 & 1.04 \\
-5140 & 202 & 207 & 2.44 \\
\hline
\end{tabular}


Table 3: Physical properties attributed to lower reservoir (less permeable granitic basement) [15], [32], [33]

\begin{tabular}{lll}
\hline Parameter & Value & Symbol \\
\hline Matrix & 1.0 & $\phi$ \\
Porosity $(\%)$ & 0.001 & $\kappa$ \\
Permeability $(\mathrm{mD})$ & 3.0 & $\lambda_{s}$ \\
Thermal conductivity $(\mathrm{W} / \mathrm{m} / \mathrm{K})$ & 850 & $C_{\rho, S}$ \\
Heat capacity $(\mathrm{J} / \mathrm{kg} / \mathrm{K})$ & 2600 & $\rho_{s}$ \\
Density $\left(\mathrm{kg} / \mathrm{m}^{3}\right)$ & & \\
Fracture & 0.1 & $\phi_{f}$ \\
Porosity $(\%)$ & 10 & $\kappa_{f}$ \\
Permeability $(\mathrm{mD})$ & 2.5 & $\lambda_{f}$ \\
Thermal conductivity $(\mathrm{W} / \mathrm{m} / \mathrm{K})$ & 750 & $C_{\rho, f}$ \\
Heat capacity $(\mathrm{J} / \mathrm{kg} / \mathrm{K})$ & 2000 & $\rho_{f}$ \\
Density $\left(\mathrm{kg} / \mathrm{m}^{3}\right)$ & & \\
\hline
\end{tabular}


Table 4: Range of values for the human-controlled parameters used in the reservoir model

\begin{tabular}{lll}
\hline Parameter & Minimum Value (-) & Maximum Value (+) \\
\hline Injection rate $(1 / \mathrm{s})$ & 10 & 70 \\
Lateral well spacing $(\mathrm{km})$ & 0.3 & 0.6 \\
Injection temperature $\left({ }^{\circ} \mathrm{C}\right)$ & 30 & 60 \\
Injection pressure $(\mathrm{MPa})$ & 10 & 25 \\
\hline
\end{tabular}


Table 5: Range of values for the naturally-occurring parameters used in the reservoir model

\begin{tabular}{lll}
\hline Parameter & Minimum Value (-) & Maximum Value (+) \\
\hline Geothermal gradient $\left({ }^{\circ} \mathrm{C} / \mathrm{km}\right)$ & 28 & 38 \\
Permeability $(\mathrm{mD})$ & 1.0 & 0.01 \\
Thermal conductivity $(\mathrm{W} / \mathrm{m} / \mathrm{K})$ & 1.0 & 3.5 \\
Porosity $(\%)$ & 10 & 40 \\
\hline
\end{tabular}


Table 6: Human-controlled parameter combinations

\begin{tabular}{|c|c|c|c|c|}
\hline $\begin{array}{c}\text { Run } \\
\text { number }\end{array}$ & $\begin{array}{c}\text { Lateral } \\
\text { well spacing }(\mathbf{k m})\end{array}$ & $\begin{array}{l}\text { Injection } \\
\text { rate }(1 / \mathrm{s})\end{array}$ & $\begin{array}{c}\text { Injection } \\
\text { temperature }\left({ }^{\circ} \mathrm{C}\right)\end{array}$ & $\begin{array}{c}\text { Injection } \\
\text { pressure (MPa) }\end{array}$ \\
\hline 1 & 0.3 & 10 & 30 & 10 \\
\hline 2 & 0.3 & 10 & 30 & 25 \\
\hline 3 & 0.3 & 10 & 60 & 10 \\
\hline 4 & 0.3 & 10 & 60 & 25 \\
\hline 5 & 0.3 & 70 & 30 & 10 \\
\hline 6 & 0.3 & 70 & 30 & 25 \\
\hline 7 & 0.3 & 70 & 60 & 10 \\
\hline 8 & 0.6 & 70 & 60 & 25 \\
\hline 9 & 0.6 & 10 & 30 & 10 \\
\hline 10 & 0.6 & 10 & 30 & 25 \\
\hline 11 & 0.6 & 10 & 60 & 10 \\
\hline 12 & 0.6 & 10 & 60 & 25 \\
\hline 13 & 0.6 & 70 & 30 & 10 \\
\hline 14 & 0.6 & 70 & 30 & 25 \\
\hline 15 & 0.6 & 70 & 60 & 10 \\
\hline 16 & 0.6 & 70 & 60 & 25 \\
\hline
\end{tabular}


Table 7: Naturally-occurring parameter combinations

\begin{tabular}{|c|c|c|c|c|}
\hline $\begin{array}{c}\text { Run } \\
\text { number }\end{array}$ & $\begin{array}{c}\text { Geothermal } \\
\text { gradient }\left({ }^{\circ} \mathrm{C} / \mathbf{k m}\right)\end{array}$ & $\begin{array}{l}\text { Permeability } \\
\text { (mD) }\end{array}$ & $\begin{array}{l}\text { Thermal conductivity } \\
\qquad(\mathrm{W} / \mathrm{m} / \mathrm{K})\end{array}$ & Porosity (\%) \\
\hline 1 & 28 & 0.01 & 1.0 & 10 \\
\hline 2 & 28 & 0.01 & 1.0 & 40 \\
\hline 3 & 28 & 0.01 & 3.5 & 10 \\
\hline 4 & 28 & 0.01 & 3.5 & 40 \\
\hline 5 & 28 & 0.01 & 1.0 & 10 \\
\hline 6 & 28 & 0.01 & 1.0 & 40 \\
\hline 7 & 28 & 0.01 & 3.5 & 10 \\
\hline 8 & 28 & 0.01 & 3.5 & 40 \\
\hline 9 & 38 & 1.0 & 1.0 & 10 \\
\hline 10 & 38 & 1.0 & 1.0 & 40 \\
\hline 11 & 38 & 1.0 & 3.5 & 10 \\
\hline 12 & 38 & 1.0 & 3.5 & 40 \\
\hline 13 & 38 & 1.0 & 1.0 & 10 \\
\hline 14 & 38 & 1.0 & 1.0 & 40 \\
\hline 15 & 38 & 1.0 & 3.5 & 10 \\
\hline 16 & 38 & 1.0 & 3.5 & 40 \\
\hline
\end{tabular}




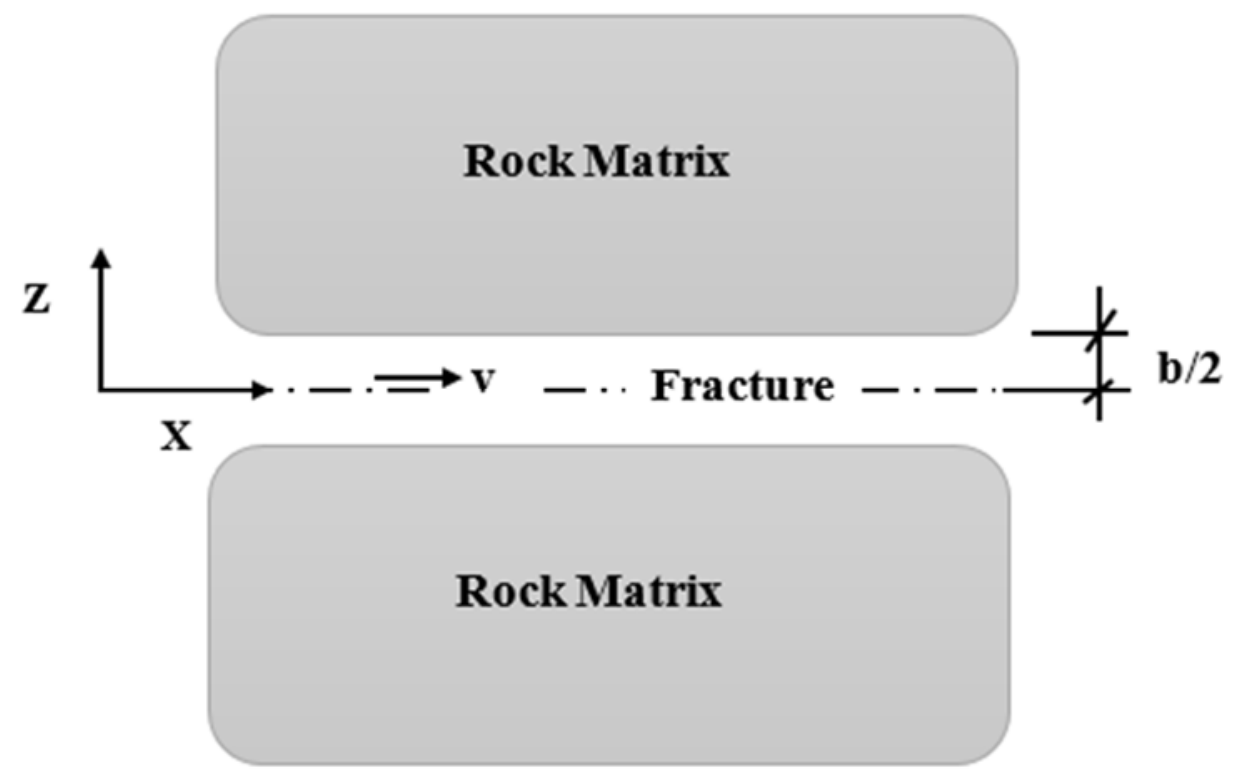

Fig. 1: Model geometry for the fracture-matrix heat transport (Adopted [19])

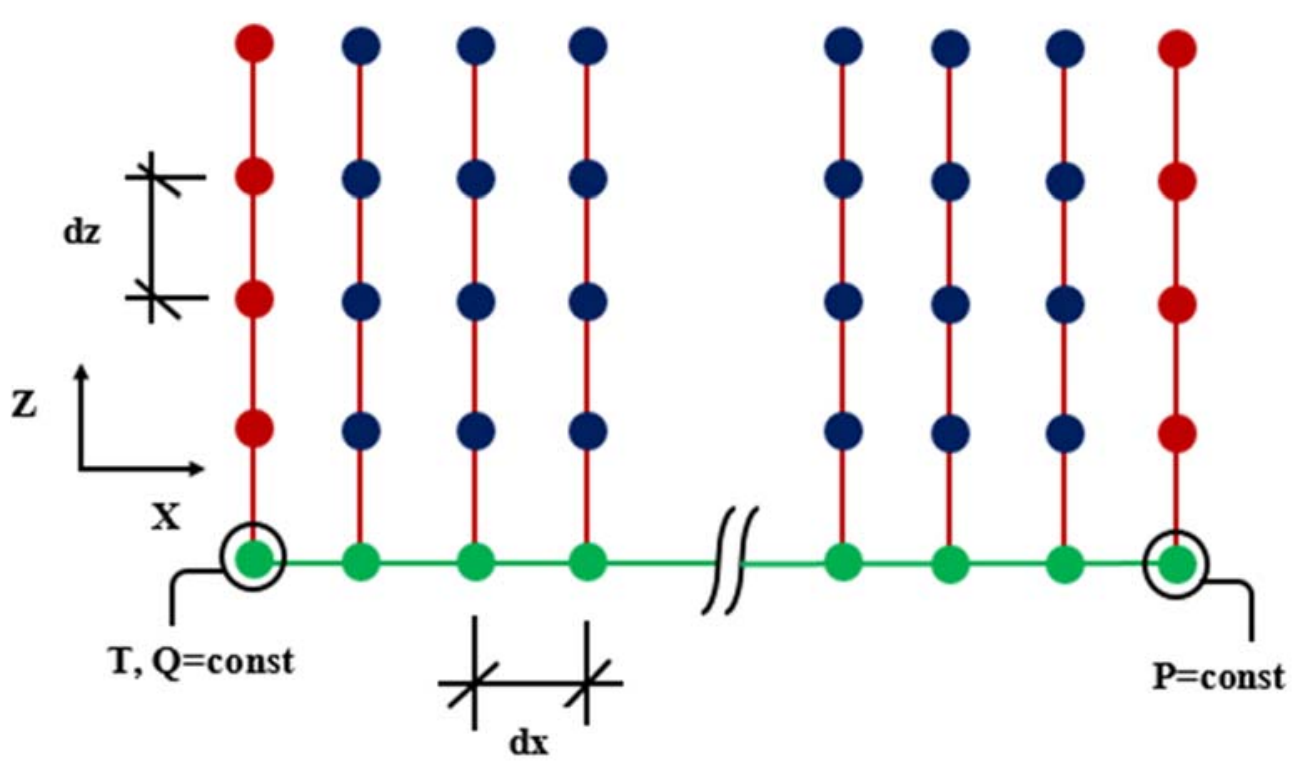

Fig. 2: Grid alignment and boundary conditions for the numerical model 


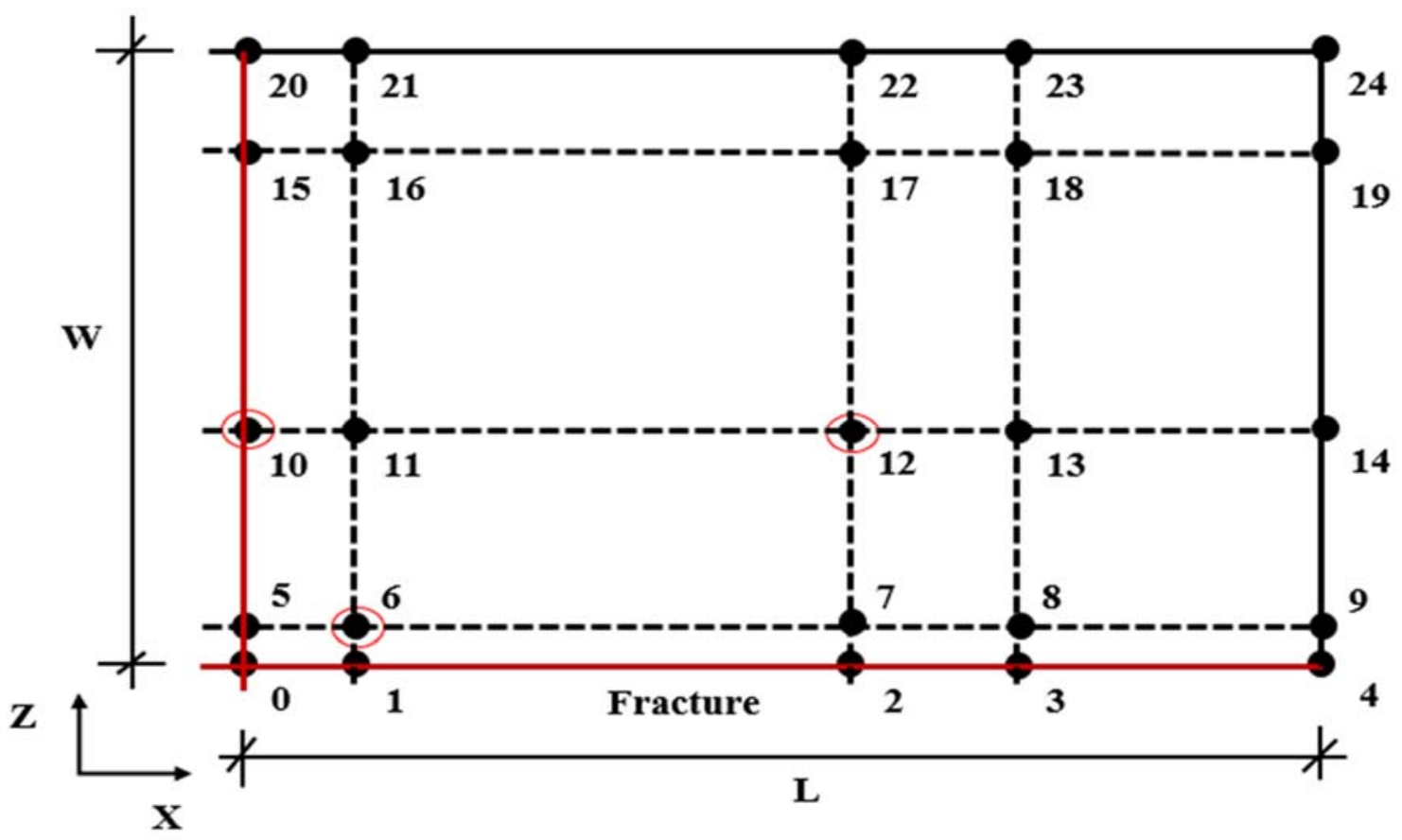

Fig. 3: Observation points positions (i.e., 6, 10, and 12) for temperature history curves

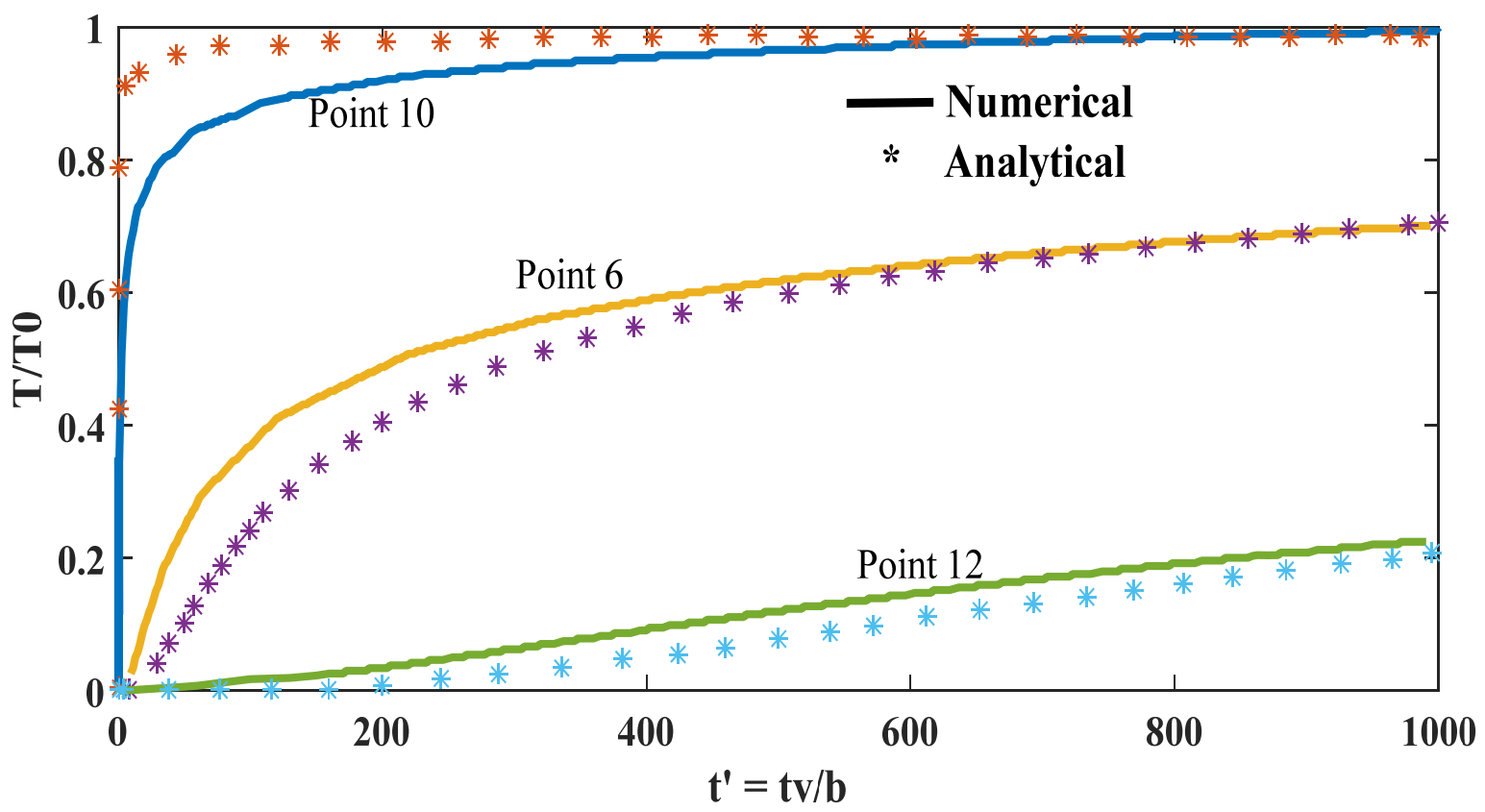

Fig. 4: Temperature history curves at certain locations in the rock matrix for both the analytical and numerical models 


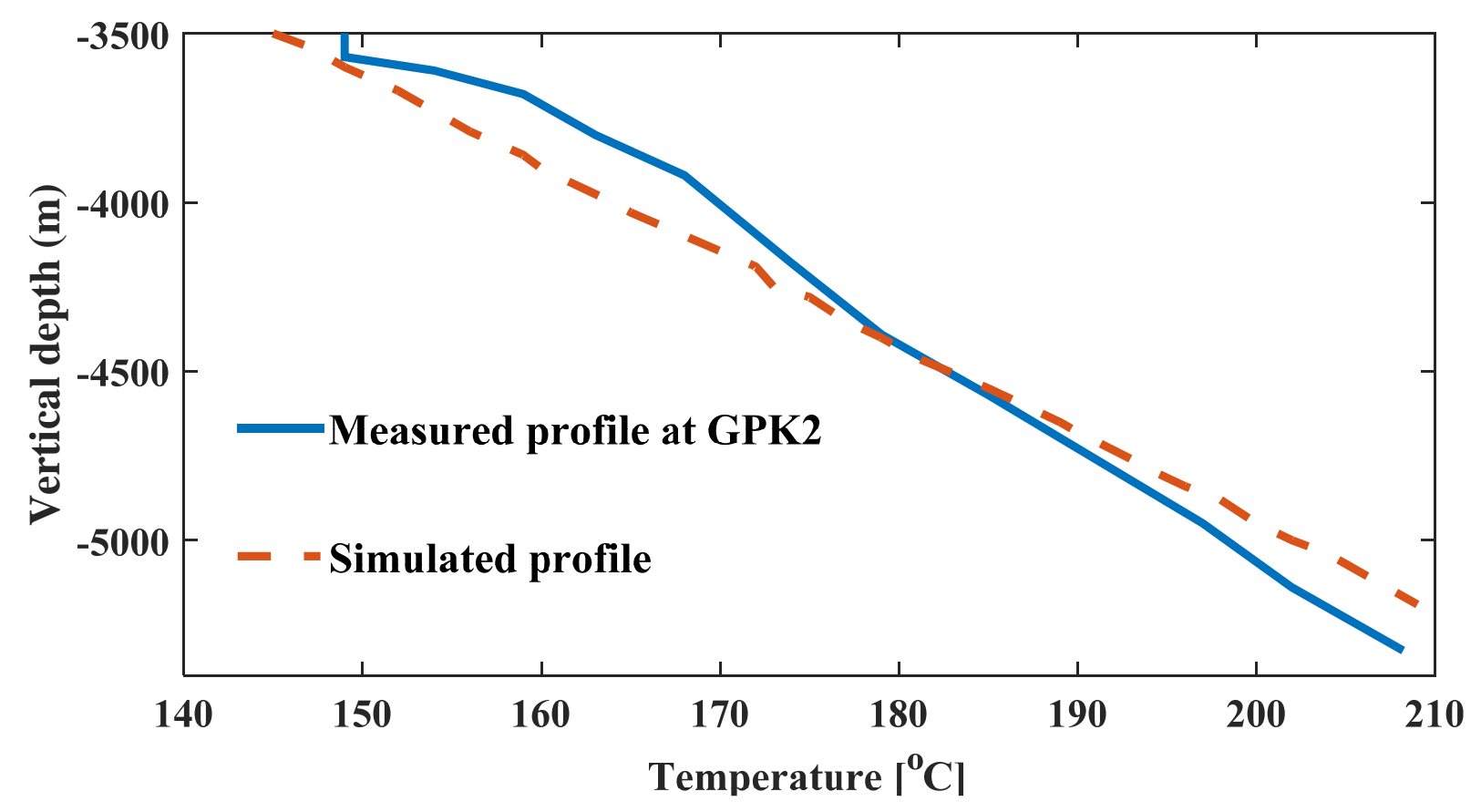

Fig. 5: Temperature profile at GPK2 well compared with simulated profile 


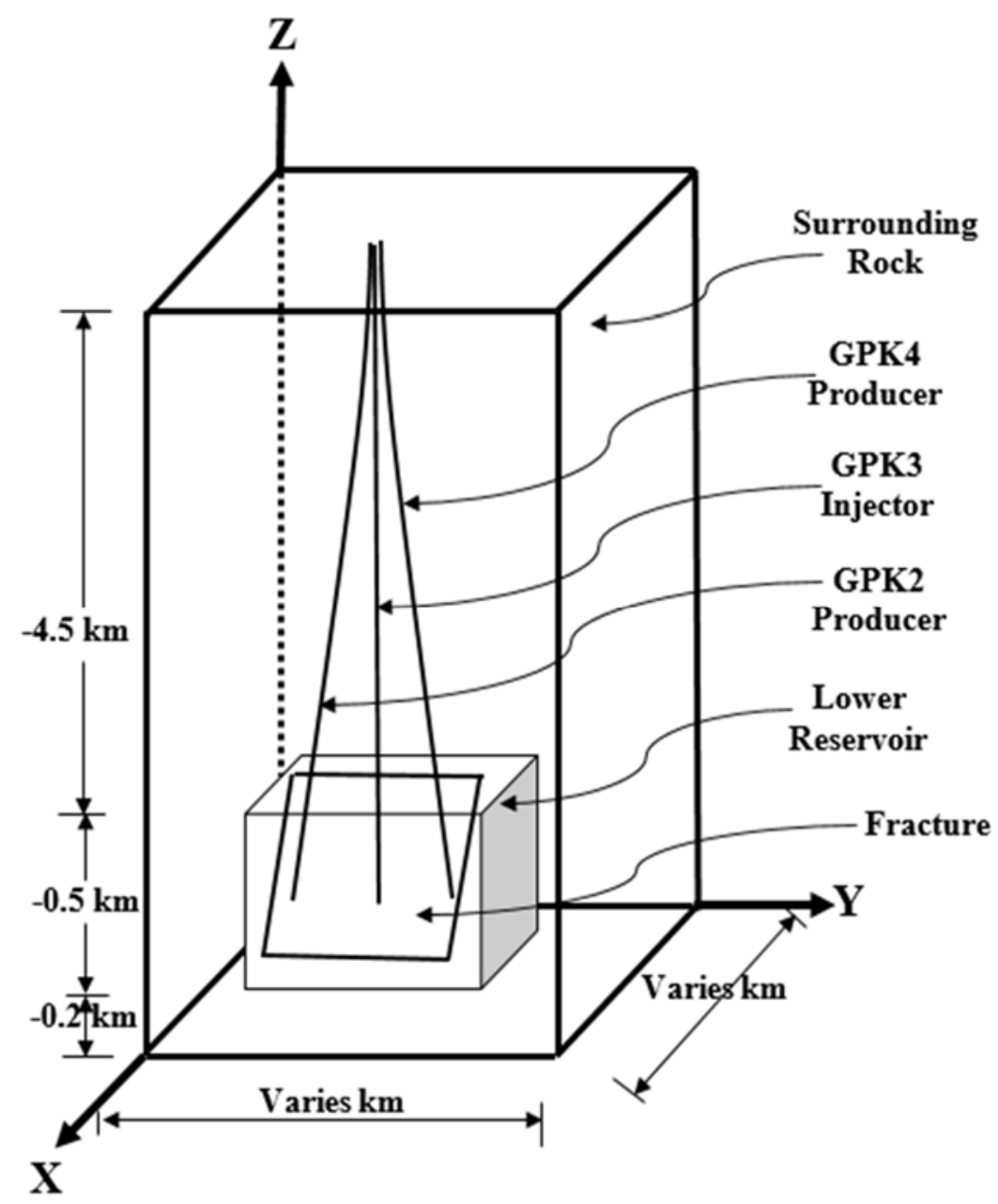

Fig. 6: Schematic representation of the Soutlz geothermal system

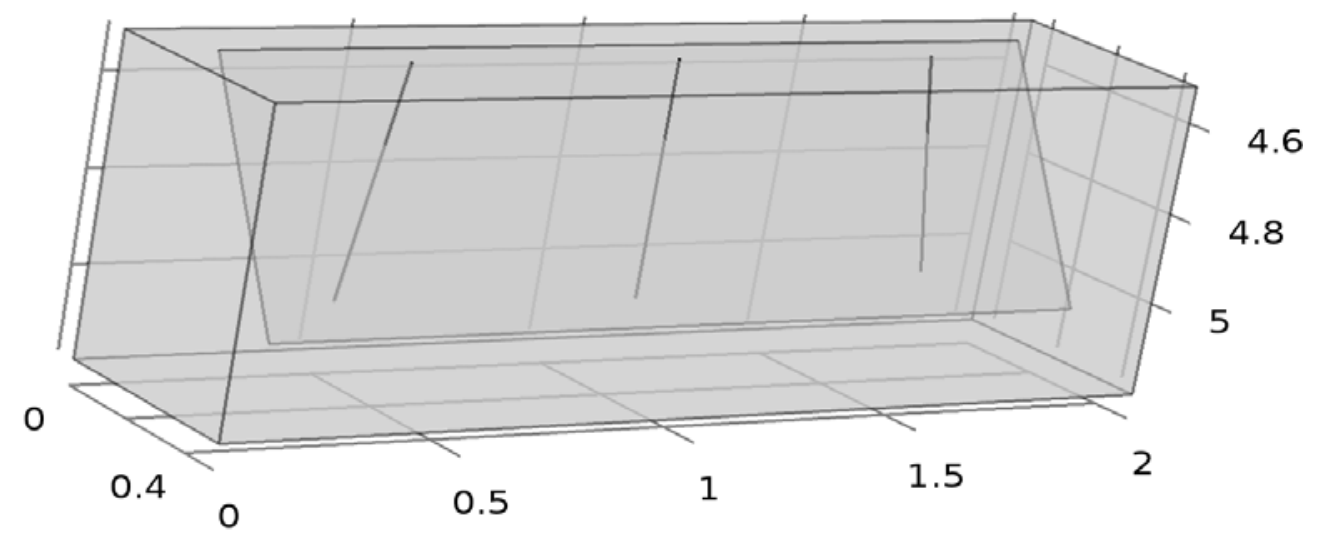

Fig. 7: Lower reservoir geometry $(\mathrm{km})$ 


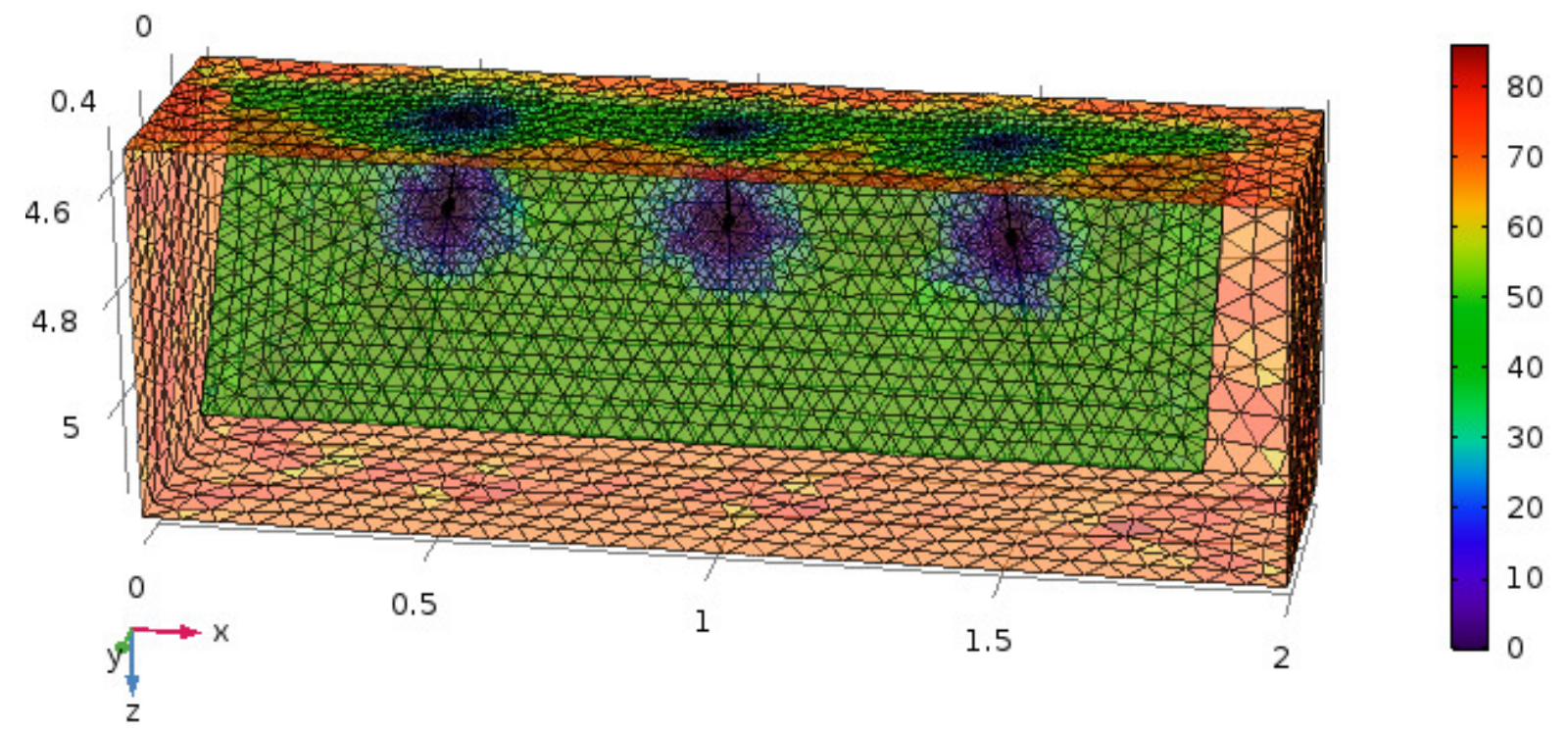

Fig. 8: Lower reservoir mesh element sizes and distributions (m) 


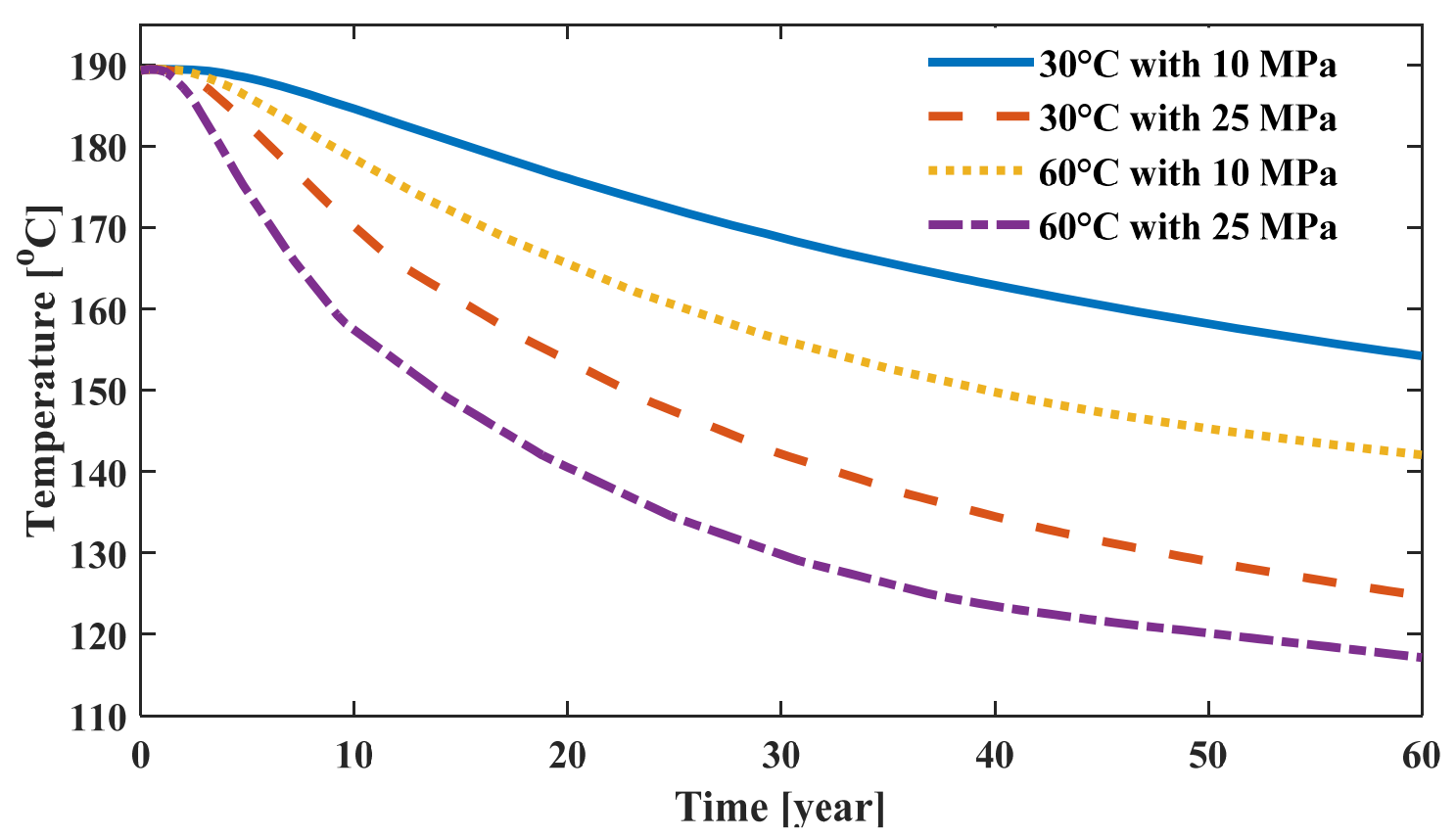

Fig. 9a: Production temperature at wellhead GPK2 with constant injection rate $10 \mathrm{l} / \mathrm{s}$ and 0.3 $\mathrm{km}$ lateral well spacing under the influence of various injection temperatures and pressures

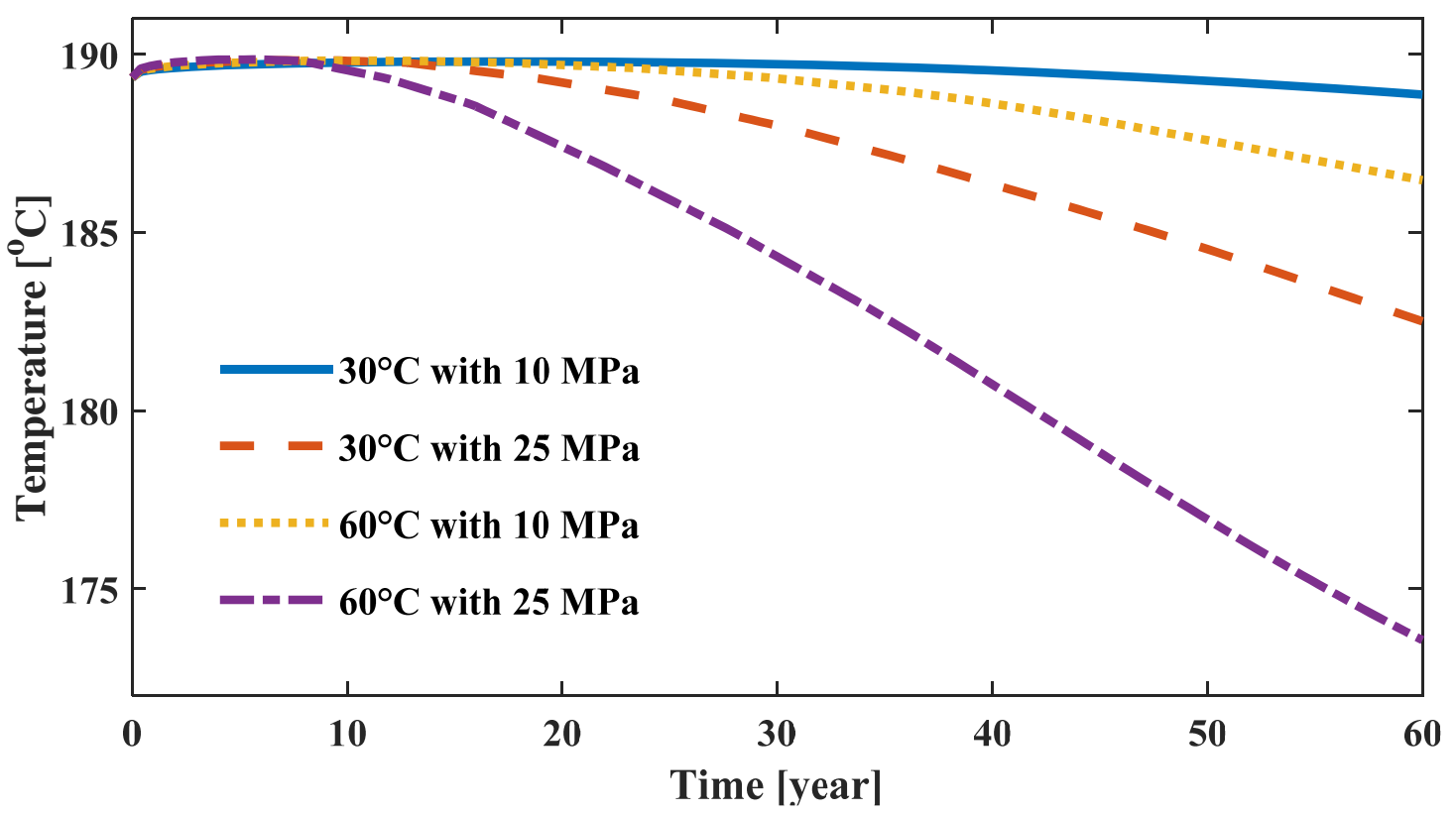

Fig. 9b: Production temperature at wellhead GPK2 with constant injection rate $10 \mathrm{l} / \mathrm{s}$ and 0.6 $\mathrm{km}$ lateral well spacing under the influence of various injection temperatures and pressures

Fig. 9: Production temperature at wellhead GPK2 for human controlled parameters under the influence of multiple parameter interaction 


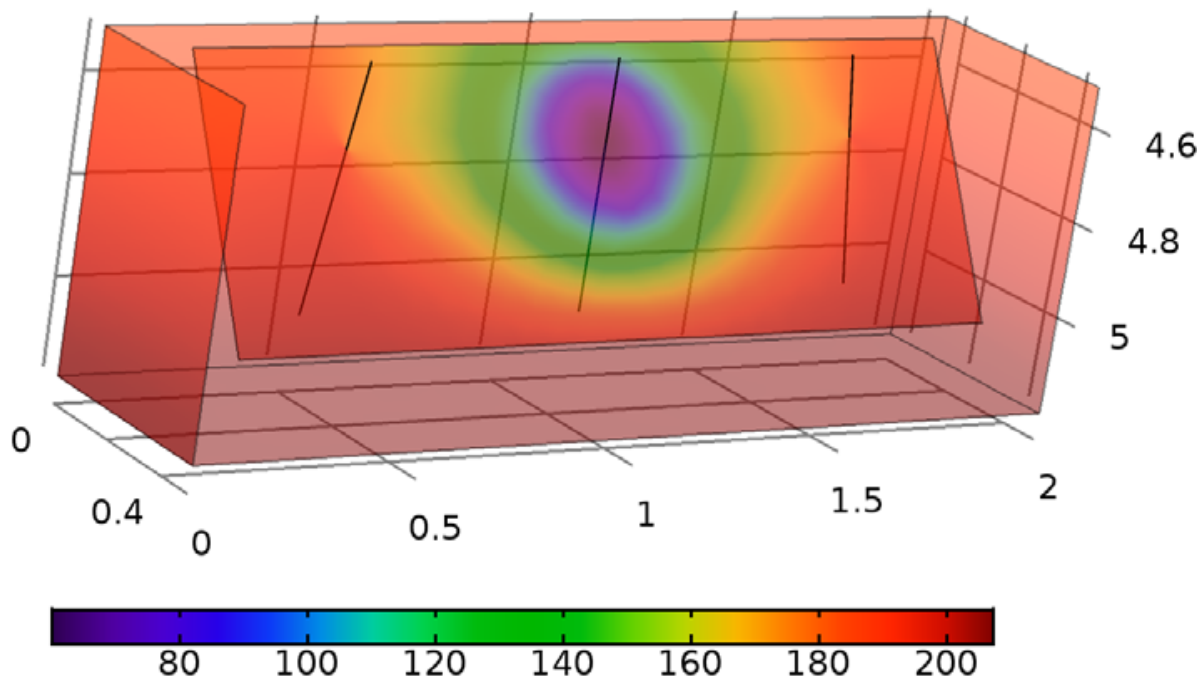

Fig. 10a: Reservoir cooling $\left({ }^{\circ} \mathrm{C}\right)$ under the effect of $60^{\circ} \mathrm{C}$ fluid injection temperature with $25 \mathrm{MPa}$ injection pressure rate

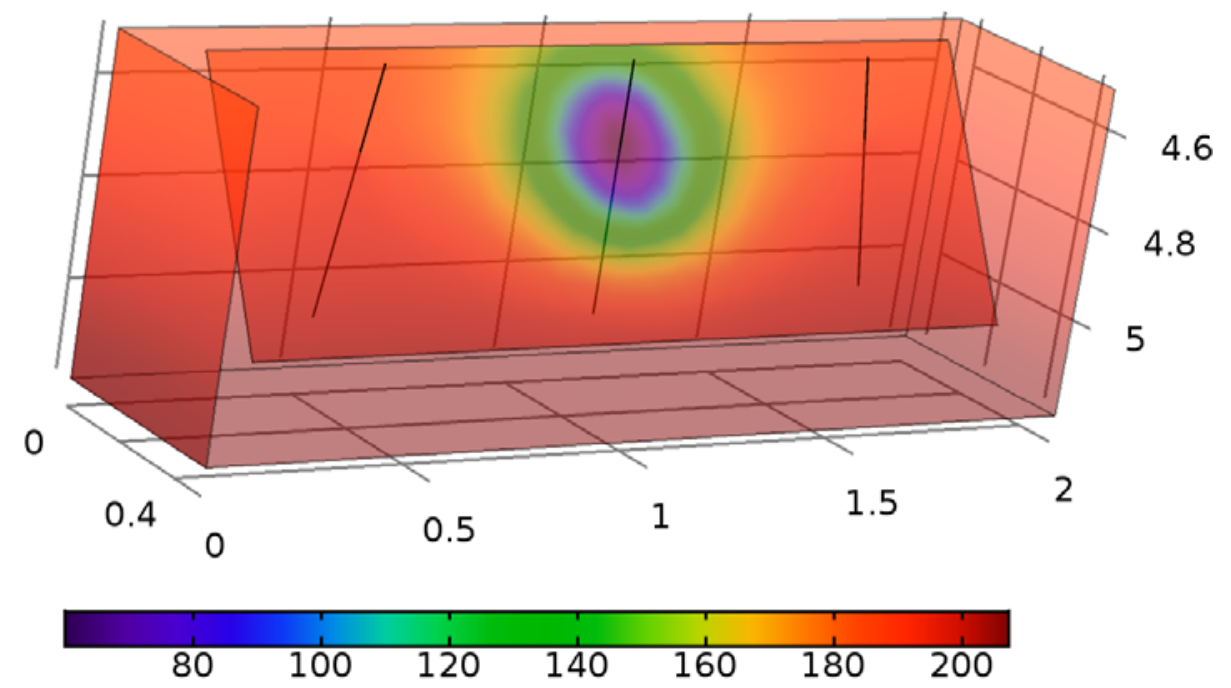

Fig. 10b: Reservoir cooling $\left({ }^{\circ} \mathrm{C}\right)$ under the effect of $60^{\circ} \mathrm{C}$ fluid injection temperature with $10 \mathrm{MPa}$ injection pressure rate 


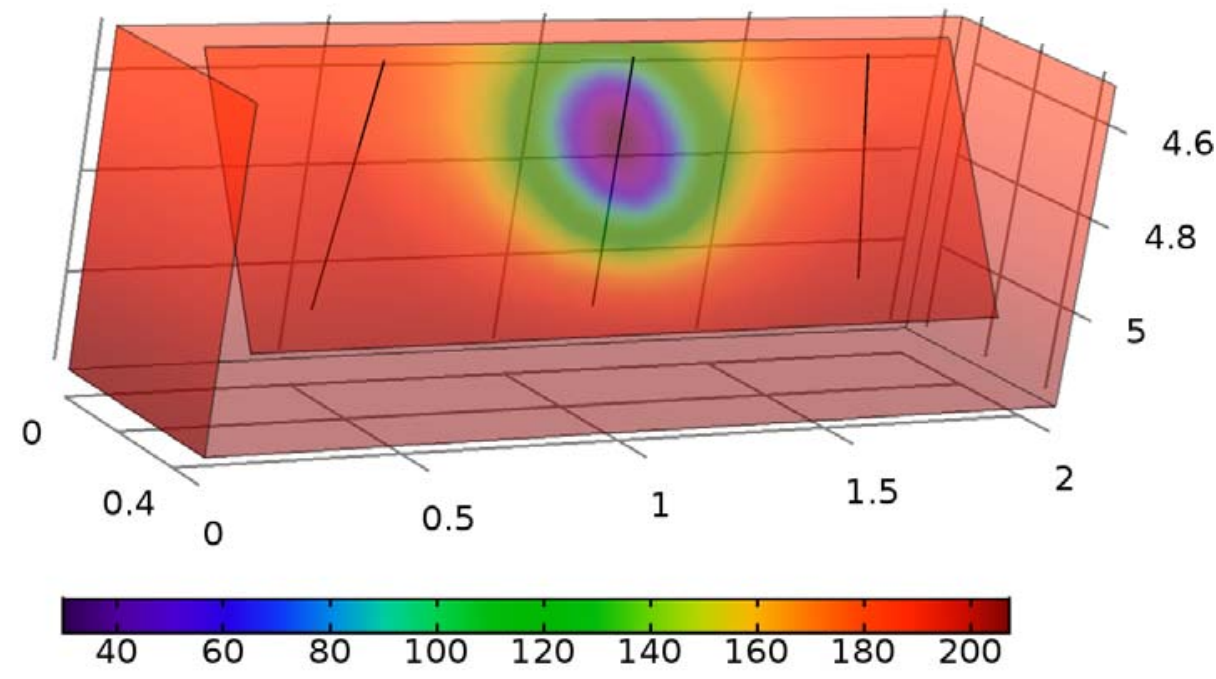

Fig. 10c: Reservoir cooling $\left({ }^{\circ} \mathrm{C}\right)$ under the effect of $30^{\circ} \mathrm{C}$ fluid injection temperature with $25 \mathrm{MPa}$ injection pressure rate

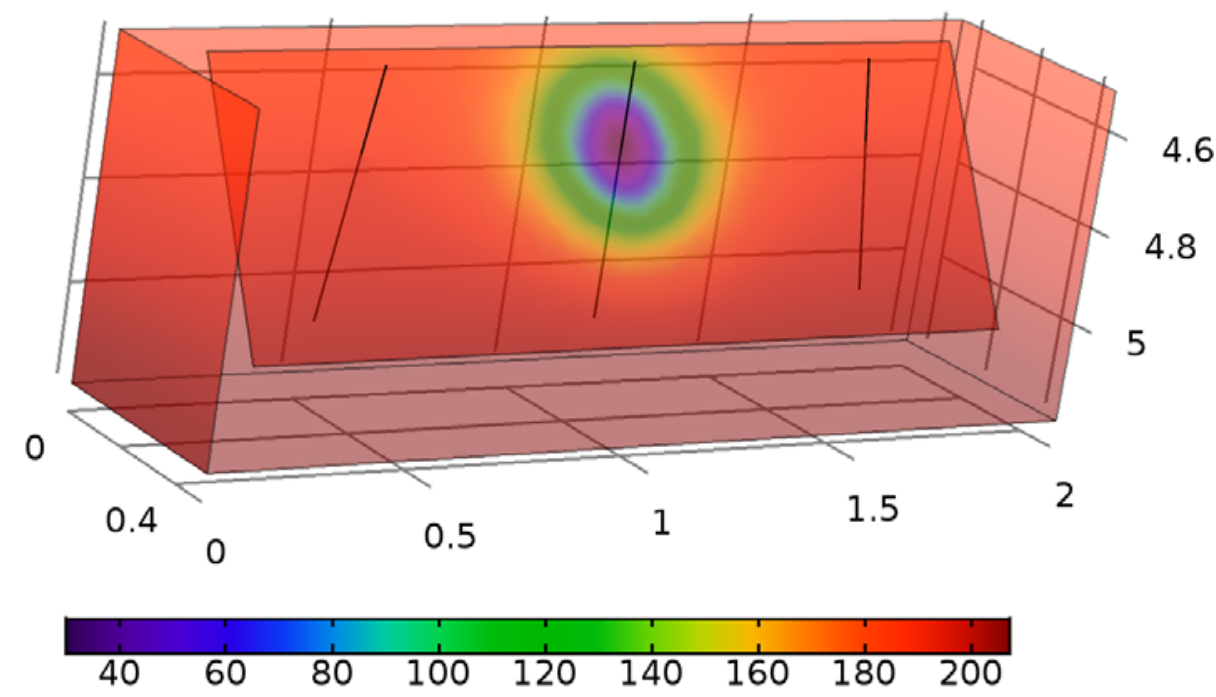

Fig. 10d: Reservoir cooling $\left({ }^{\circ} \mathrm{C}\right)$ under the effect of $30^{\circ} \mathrm{C}$ fluid injection temperature with $10 \mathrm{MPa}$ injection pressure rate

Figure 10: Reservoir cooling $\left({ }^{\circ} \mathrm{C}\right)$ as a function of fluid injection temperature and pressure rate after 60 years of simulation 


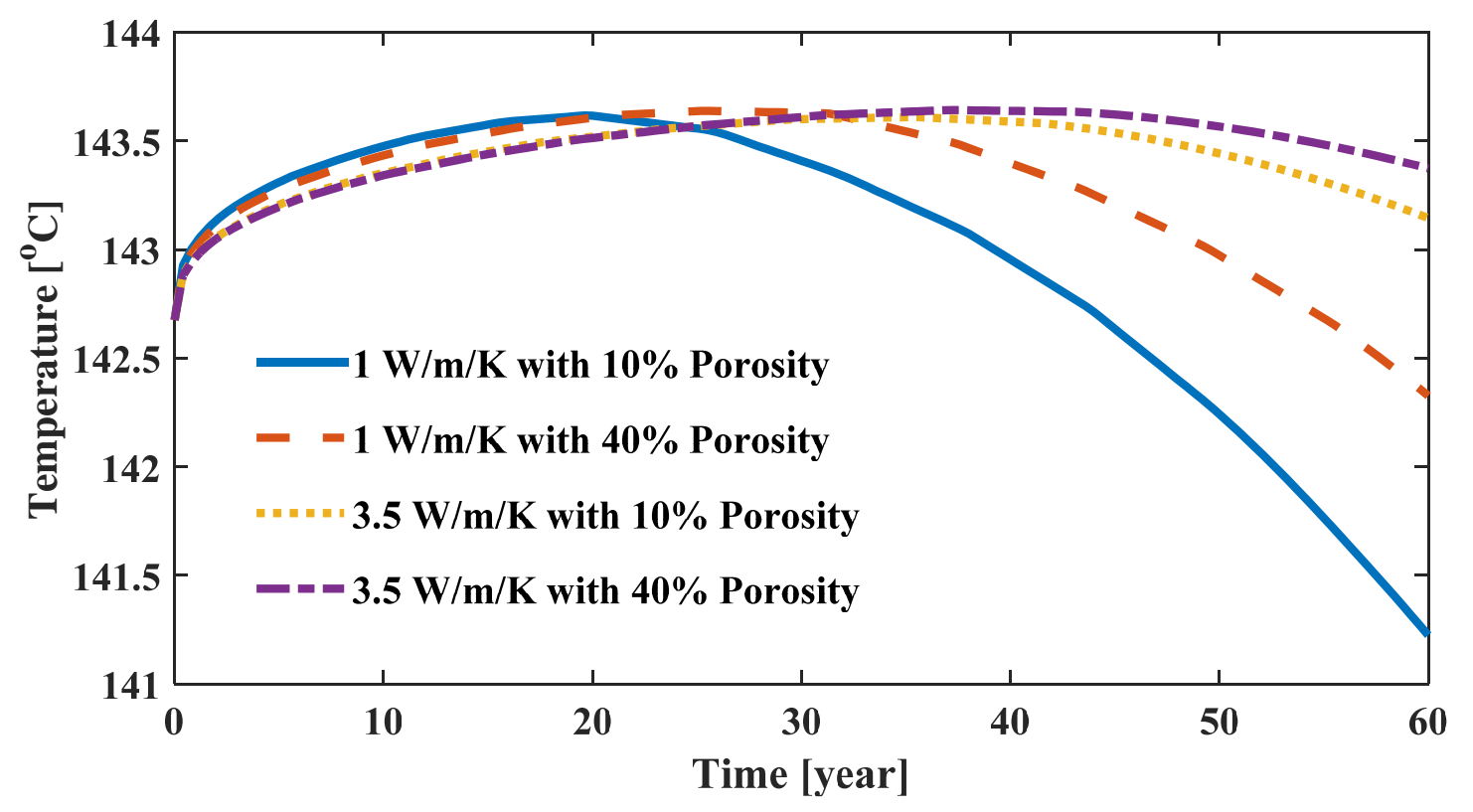

Fig. 11a: Production temperature at wellhead GPK2 with constant geothermal gradient $28^{\circ} \mathrm{C} / \mathrm{km}$ and $1 \mathrm{mD}$ permeability under the influence of various thermal conductivities and porosities

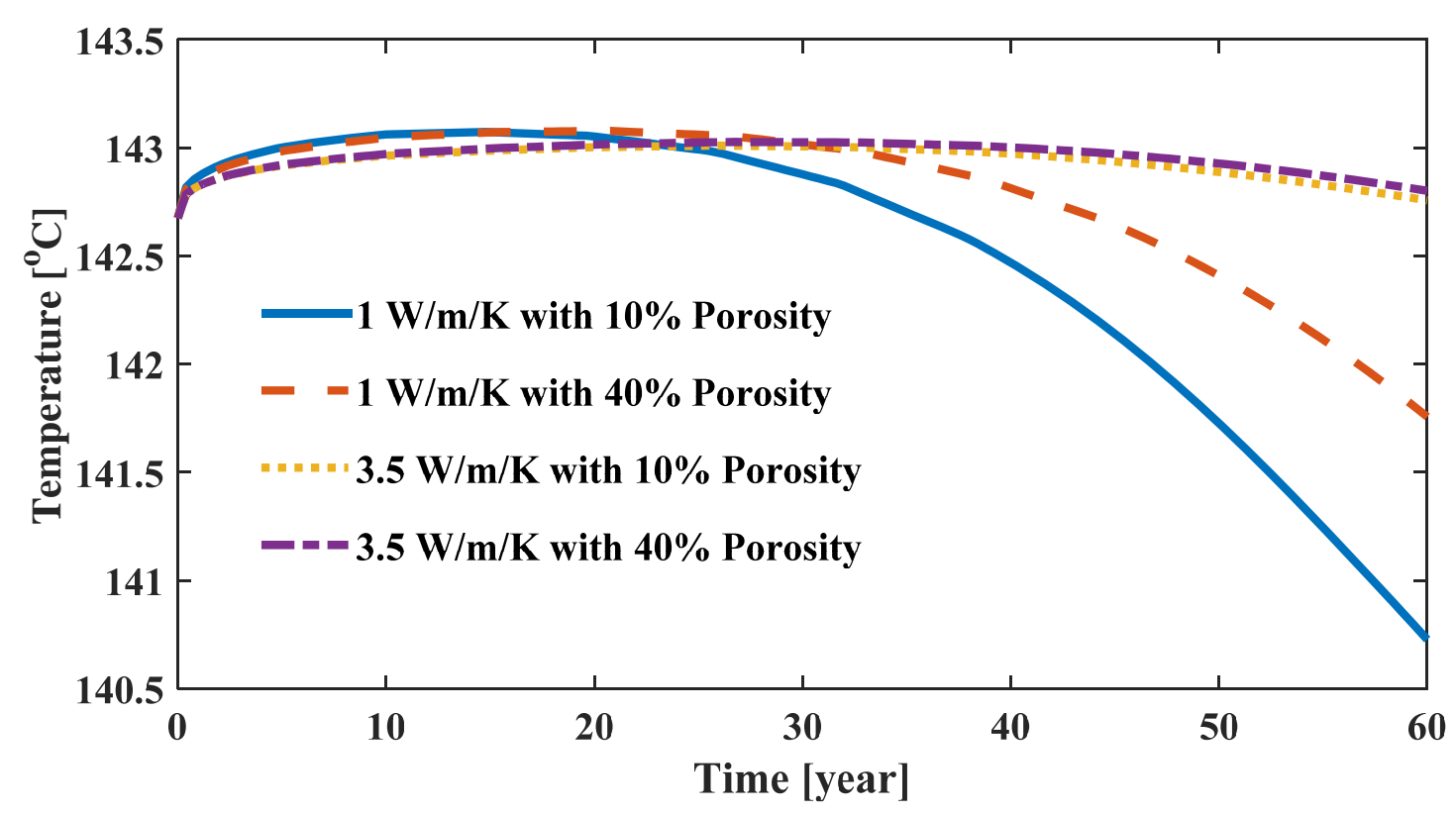

Fig. 11b: Production temperature at wellhead GPK2 with constant geothermal gradient $28^{\circ} \mathrm{C} / \mathrm{km}$ and $0.01 \mathrm{mD}$ permeability under the influence of various thermal conductivities and porosities 


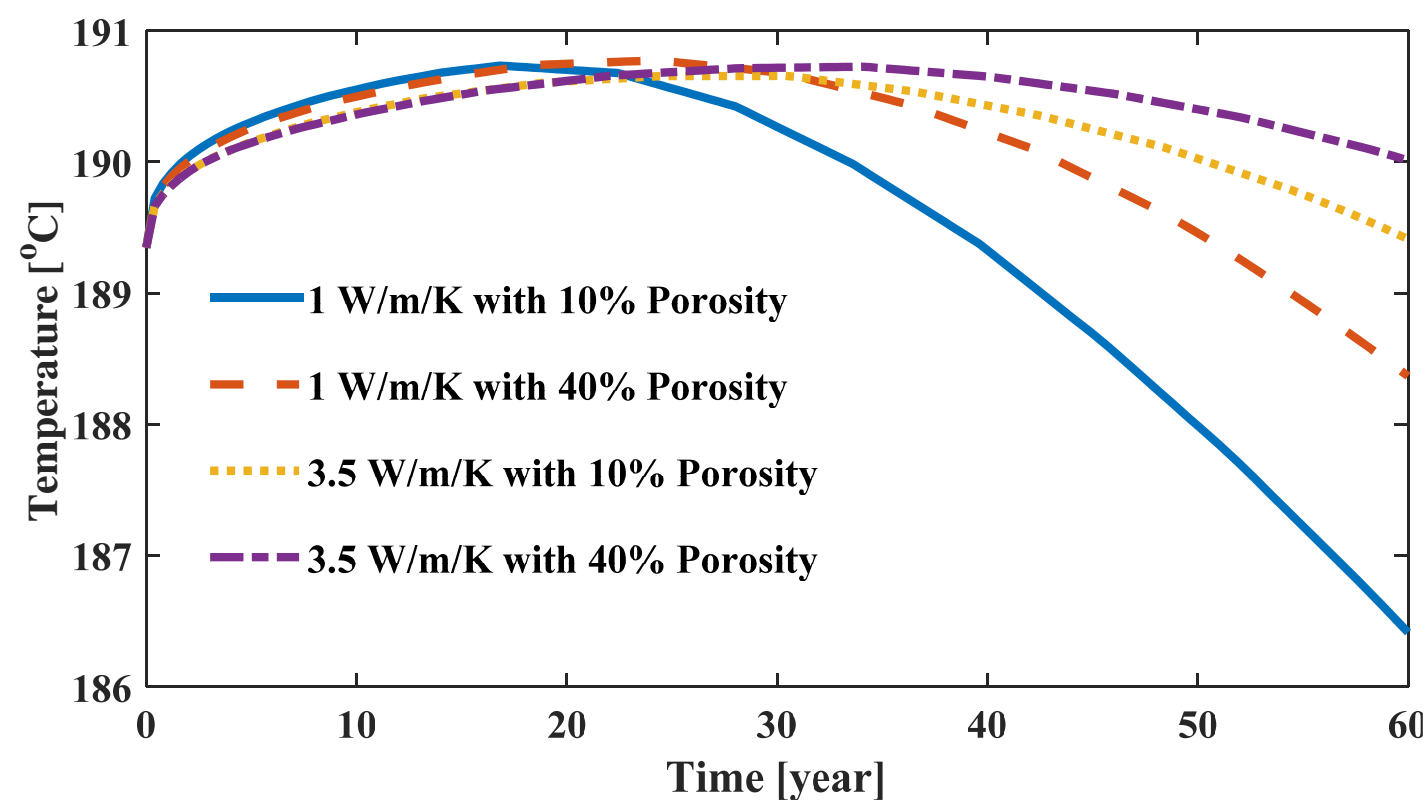

Fig. 11c: Production temperature at wellhead GPK2 with constant geothermal gradient $38^{\circ} \mathrm{C} / \mathrm{km}$ and $1 \mathrm{mD}$ permeability under the influence of various thermal conductivities and porosities

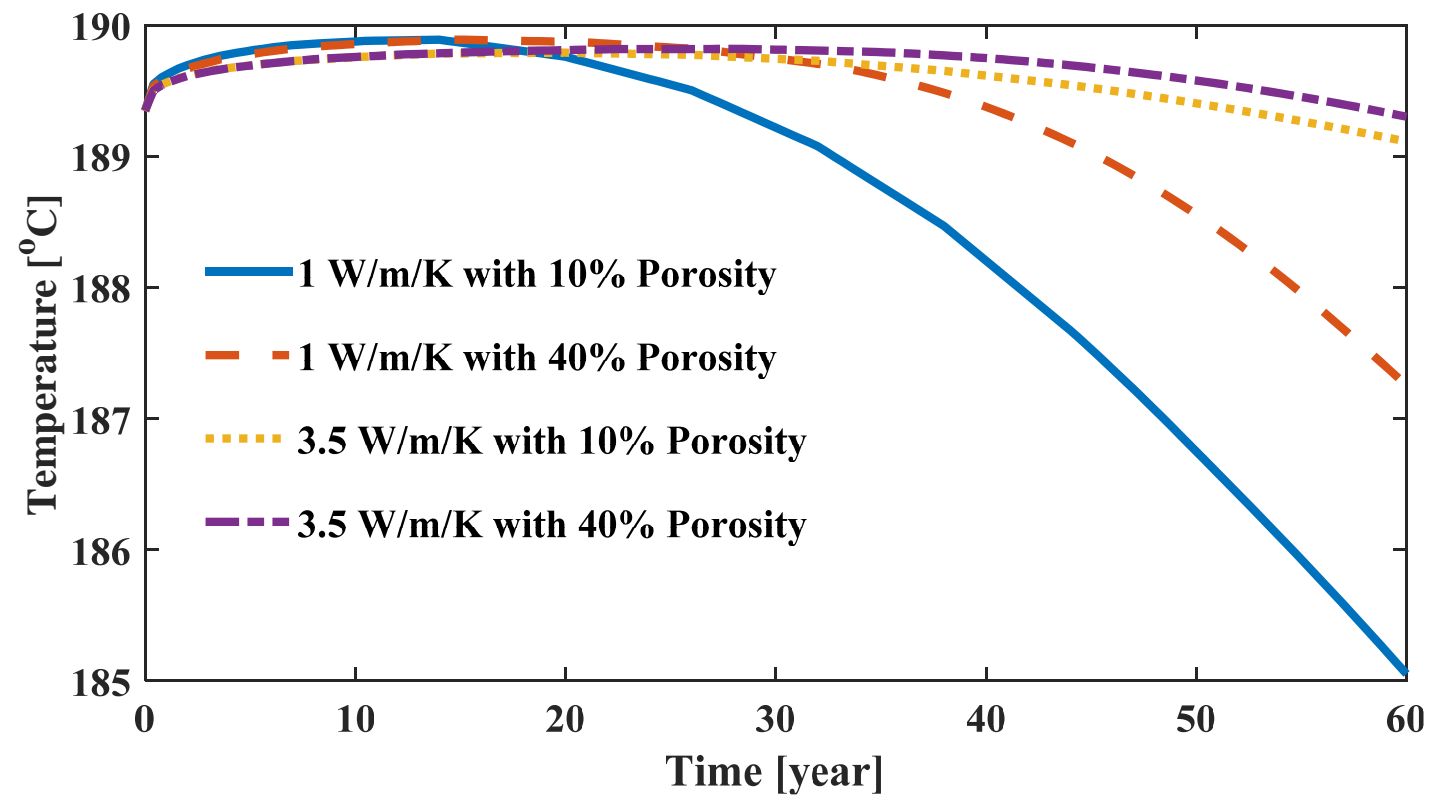

Fig. 11d: Production temperature at wellhead GPK2 with constant geothermal gradient $38^{\circ} \mathrm{C} / \mathrm{km}$ and $0.01 \mathrm{mD}$ permeability under the influence of various thermal conductivities and porosities

Fig. 11: Production temperature at wellhead GPK2 for naturally occurring parameters under the influence of multiple parameter interaction 